\title{
Yélî Dnye and the Theory of Basic Color Terms
}

The theory of basic color terms was a crucial factor in the demise of linguistic relativity. The theory is now once again under scrutiny and fundamental revision. This article details a case study that undermines one of the central claims of the classical theory, namely that languages universally treat color as a unitary domain, to be exhaustively named. Taken together with other cases, the study suggests that a number of languages have only an incipient color terminology, raising doubts about the linguistic universality of such terminology.

\section{Color Terms: The State of the Art}

Nosingle work has done more to undermine the doctrine of linguistic relativity than Berlin and Kay's Basic Color Terms (1991). ${ }^{1}$ Indeed, it has carried a burden surely greater than ever intended by the authors, for it has often been assumed that if striking universals can be shown in the color domain, then we may assume that we will find comparable universals in most other domains (Rosch 1977:519). Outside linguistic anthropology, the original theory is now embedded in the preconceptions of many fields, from psychology to art history. But in fact, in the interval a great deal of further data has been collected, requiring significant shifts in the basic claims, with important consequences for claims about linguistic relativity. There have long been critics, but the new range of data and the new interest in relativity have reawakened serious debate: color is back in the news, in linguistic anthropology, cognitive science, philosophy, and culture history (see, e.g., Byrne and Hilbert 1997; Gage 1999; Hardin and Maffi 1997; Lamb and Bourriau 1995; MacLaury 1997; Saunders and van Brakel 1997). A serious review of 
the literature is beyond the scope or purpose of this essay (see, e.g., MacLaury 1997), but a brief summary of the recent developments may be useful.

\section{The Theory of Basic Color Terms}

The theory of basic color terms (henceforth BCTs) has gone through the following developments:

1. The Original Theory. Berlin and Kay (1991) first defined the notion of a "BCT," essentially a monolexemic term with primary color reference (but see below). Speakers from 20 different languages were shown an array of 330 maximally saturated hues from the Munsell color chart and asked to choose the best exemplars of their (previously elicited) BCTs and the range of their extensions. ${ }^{2}$ The BCTs of these languages were shown each to have focal hues (best exemplars) in nearly the identical areas of the color chart (if they have BCTs in that hue area at all). In contrast to focal hues, the range or category boundaries of BCTs were shown to be variable and less revealing. Surveying the literature on nearly eighty further languages, they established an implicational sequence as in Table 1 (where, for example, possession of a term based on Red implies the possession of terms based on White and Black), which can also be read as a path of "evolutionary" stages. $^{3}$

Various modifications followed: in Kay 1975, the green in Stages 3 and 4 became "grue" (i.e., Green and Blue undifferentiated) and Grey was allowed to appear earlier.

2. Composite Categories. Kay and McDaniel (1978), in response to data in, for example, Heider 1972, introduced new ideas about the reference of BCTs. In Berlin and Kay, BCTs have primary reference to categories with loose boundaries but clearly defined, unique foci. In Kay and McDaniel, BCTs refer to categories, each of which is either a fuzzy set based on a single hue focus, or a union or intersection of two (at most three) such fuzzy sets. Thus, in contrast to Berlin and Kay, in Kay and McDaniel a single BCT may have more than one focus, when the term is said to be "composite"-an example being Dani white/warm, which may be focused either in White or Red. Kay and McDaniel noted only four such composites: light-warm (focused on White, Red, or Yellow), warm (focused on Red or Yellow),

Table 1

Implicational scale of basic color terms.

\begin{tabular}{|c|c|c|c|c|c|c|c|}
\hline \multirow[t]{2}{*}{ Stages } & $\begin{array}{c}\text { I } \\
\text { White }\end{array}$ & II & $\begin{array}{c}\text { III } \\
\text { Green }\end{array}$ & $\begin{array}{c}\text { IV } \\
\text { Green }\end{array}$ & V & VI & $\begin{array}{c}\text { VII } \\
\text { Purple }\end{array}$ \\
\hline & $\begin{array}{c}\& \\
\text { Black }\end{array}$ & $<$ Red & $\begin{array}{l}<\text { or } \\
\text { Yellow }\end{array}$ & $\begin{array}{l}<\& \& \\
\text { Yellow }\end{array}$ & $<$ Blue & $<$ Brown & $\begin{array}{c}\text { Pink } \\
\text { Orange } \\
\text { Grey }\end{array}$ \\
\hline
\end{tabular}


dark-cool (focused on Black, Green, or Blue), and grue (focused on Green or Blue). Kay and McDaniel go on to relate the foci to the four Hering opponent colors, Red, Green, Blue, Yellow, together with Black and White (these six colors they call "fundamental neural response categories" or FNRs; others call them "Hering primaries" or "the landmark colors" [Miller and Johnson-Laird 1976:21, 334]). Kay and McDaniel then restate the sequence of possible BCT inventories: in Stage 1 "Black" and "White" are in fact composites with three foci each (White/Red/Yellow versus Black/Green/Blue); in Stage 2 the three BCTs have foci in White, Red/Yellow, Black/Green/Blue; and thereafter these last two composites are successively broken down, till we have a Stage 5 system without composites, just as in Berlin and Kay. After that all further terms are intersections of fuzzy sets, like English brown, with a focus between Yellow and Black. Taken as an evolutionary sequence, the essential predicted pattern then is for composite categories to be successively removed and resolved into the six FNRs (Hering primaries) and thereafter for the formation of derived categories between FNRs, perceptual blends, as it were (like "brown" and "orange").

3. Field Studies. Careful field studies in the 1970s (e.g., Dougherty 1977; Harkness 1973; Heider 1972) suggested that there was very considerable variation in the number and interpretation of BCTs to be found in small speech communities. This variation was interpreted as systematic sociolinguistic variation constrained by the evolutionary sequence of BCTs (Kay 1975). ${ }^{4}$

4. The World Color Survey (WCS). The WCS and associated work have thrown up a range of further findings (see Kay et al. 1991; Kay et al. 1997; MacLaury 1997). Although the stimulus materials are the same in all this work, being 330 maximally saturated hues from the Munsell array, in the WCS these chips are shown one by one in random order and named without first screening out just the BCTs. BCTs, non-BCTs, and modifiers are therefore also elicited. Foci are then elicited in the same way as before, by pointing to an array showing all 330 chips (as in Berlin and Kay). BCTs and their references are extracted from all this data. Findings include the following:

- Composites are formed from adjacent foci but never cross the yellow barrier (e.g., never include together focal Red/Yellow/Green); this allows just nine possible composites, of which eight are now attested.

- Yellow-Green composites occur, even though these two foci are never in the same category at Stage 2, posing a major obstacle for the theory of evolutionary stages (see MacLaury 1987). Yellow/Green/Blue composites also occur, even though Yellow and Blue are Hering opponent colors (the solution Kay and Maffi 1999 gives to this puzzle is described in the conclusions).

In sum, the four central claims of this line of work are that 
1. all languages have BCTs, a small set of color words that exhaustively partition the color space;

2. foci for BCTs tend to be located in $\mathbf{1 1}$ predetermined loci in the color chart;

3. there is an implicational scale over the three kinds of categories (based on FNRs, composites of FNRs, and intersections of FNRs) that can be constructed, such that if a language has just $n$ BCTs it can be predicted within a small range what they will be; and

4. the FNR hues are psychophysically salient for good physiological reasons.

There is a great deal of further work that shares essential methods and goals of the WCS or explores variant methods (see, e.g., Davies et al. 1992). But let us now turn to the critical literature that has grown up around the BCT theory.

\section{The Critiques of BCT Theory}

Berlin and Kay 1991 has given rise to an immense secondary literature, which contains not only much critical commentary but also now long forgotten constructive criticism from the point of field methodology (see, e.g., Berlin and Berlin 1975; Kuschel and Monberg 1974). Lucy (1997a) and others (see Saunders and van Brakel 1997) have offered a sustained critique of this work (see Kay and Berlin 1997 for some response). The grounds of complaint that have been voiced include the following:

1. Such studies are rarely accompanied by sophisticated work on the linguistics of the terms elicited; in many cases we do not even know whether the terms come from the same form class or not. ${ }^{5}$

2. The procedure imports a referential base for cross-linguistic comparison that may in fact be irrelevant to, or cross-cut, semantic organization in the languages to be studied; worse, choosing a stimulus set that happens to be relevant to our own language, and imposing lexicalization criteria for BCTs based on English, may guarantee that what we find "out there" looks just like what we have "here" (Lucy 1997a).

3. Many languages have systematic systems of reference to surface physical properties that treat color in fundamentally different ways from, say, English, for example, combining color with other surface properties, ${ }^{7}$ but these systems are either excluded from consideration by the definition of BCT, or worse, are included but misanalyzed by virtue of the color-only stimulus materials (see, e.g., Lyons 1995; Wierzbicka 1996).

4. The method of work can therefore not support the conclusions usually adopted, namely, that (a) all languages treat the naming of color following a universal set of constraints and (b) linguistic relativity has been effectively disproved, at least for this domain. To show conclusion (a) one would need to eliminate the possibility that one is obtaining patterned adaptations of different semantic systems to a single set 
of salient psychophysical stimuli, and to show conclusion (b) one would need to investigate the reverse effect, not of psychophysics on language, but of language on psychological coding or reaction. Working from a restricted referential domain to language coding is not the way to pursue semantic universals or to investigate the relation between language and thought (see Lucy 1992, 1997a, 1997b).

To remedy, or at least ameliorate, the defects of the Berlin and Kay paradigm of research one would need, on this view, to do at least the following:

1. Proper Linguistic Analysis. For each language, on a language-internal basis, the following should be ascertained before cross-linguistic comparison:

(a) the syntax, microsyntax (derivational and collocational possibilities as in redden versus *greenen, deep red versus *deep pink, blue-green versus "green-blue, and so forth), morphology, and structural semantics (sense relations) of the word classes that have at least something to do with hue; ${ }^{8}$

(b) the typical use and full referential range of each expression, investigated without restricting oneself to a preset stimulus array, noting, for example, how and in what contexts color (and other surface) contrasts are made; and

(c) a definition of the linguistic domain for comparison, as in the notion of BCT, based on an adequate sampling of linguistic form classes and semantic fields, not on a priori stipulation.

2. Proper Perceptual and Cognitive Research. To address the linguistic relativity issues, further cross-cultural work would be required:

(a) better information on the distribution of color vision variation in different human populations (see, e.g., Bornstein 1973; Furbee et al. 1997; Sacks 1996); and

(b) latency and classification tasks, extensions of the sort already explored with English speakers or in limited cross-linguistic studies by Kay and Kempton (1984) and Lucy and Shweder (1979), among others.

There have been a host of detailed critiques of other points. The definition of $B C T$ has long been a matter of controversy (Crawford 1982; Davies and Corbet 1995; Maffi 1990; Moss 1989). It has been claimed that the Munsell array used in most of these investigations demonstrably biases the outcome in favor of the 11 focals (Lucy and Shweder 1979). ${ }^{9}$ Odd composites, like Ainu $h u$ "red-green" or the Pacific Northwest's "yellow-green" appear to violate the theory (MacLaury 1987; Moss 1989). The physiological basis for the FNRs has been questioned (e.g., D'Andrade 1989; Saunders and van Brakel 1997).

The evolutionary sequence has also come in for criticism (Lucy 1997a; Saunders and van Brakel 1997). And, a point of special interest here, it has been claimed that a different kind of evolutionary sequence can be discerned historically, where languages only slowly come to fractionate out hue-based terms, in response to cultural factors (Casson 1977; Lyons 1995, 1999; MacLaury 1992). On this view, in societies with simple color technology, 
color terms may generally have restricted application (cf. blonde of hair), may combine hue and other properties like surface patterns (cf. roan, brown interspersed with white) or desiccation (cf. Old Germanic saur, yellow/dry), and may even have primary reference to brightness rather than hue. Such terms may only slowly under pressure of interests in dye and paint come to have context-independent, abstract reference to hues, forming an exhaustive partition of a domain of color. This view has been dubbed the "Emergence Hypothesis" by Kay (1999) and Kay and Maffi (1999) and is central to what follows.

\section{The Relevance of the Findings in This Article}

The research reported here was undertaken specifically to test the current theory of basic color terms and to assess the various grounds for skepticism, in a culture where color terms are clearly not salient. The findings bear on the issues above in the following ways: In certain ways, the study supports the much replicated basic findings of BCT theory, for example, that white, black, and then red descriptors are the first systematic color terms to get lexicalized. In other respects, however, the data raise various challenges for BCT theory as it stands:

- The data do not support the fundamental assumption that all languages have dedicated terms that exhaustively partition and describe the perceptible color space.

- They do not fit the predictions for composite categories in systems with only a few color terms.

- Nor do they support the idea that a clean distinction exists between BCTs and referent-based similes for hue-instead the less canonical expressions may hedge in the more lexicalized ones.

- Significant degrees of speaker variation exist, which do not, on the face of it, look like systematic sociolinguistic variation.

Finally, the data support a rival interpretation of the evolution of basic color terms. In BCT theory it has been assumed that all cultures possess BCTs that exhaustively name the color space and the evolutionary progression is simply a matter of further subdivision of the space. In the rival theory, color lexica evolve out of less specialized vocabulary under cultural pressures and thus initially may collapse coloric and noncoloric information or fail to cover the color space (Lyons 1995, 1999). This view is inconsistent with the largely implicit assumption in BCT theory that the color spectrum constitutes so salient a perceptual field that all languages must systematically and exhaustively lexicalize color predicates. It would allow that in some languages color-related vocabulary is linguistically less salient-(a) not being clearly organized within a single form class, (b) failing to exhaustively cover the color space, and (c) having variable members with variable intensions and varied extensions. Whether this interpretation of color terms emerging out of noncoloric expressions still fits reasonably well with the rest of the theory is a matter to which we will return in the conclusions. 
In passing, I shall try to assess two of the critical issues raised by detractors of Berlin and Kay and WCS, namely whether careful linguistic analysis is likely to undermine BCT theory, and whether the procedures used by $\mathrm{BCT}$ theorists are likely to yield artifactual results.

\section{Rossel Island Language and Culture}

There is still a paucity of in-depth field studies of color terminology undertaken in the context of broad ethnographic and linguistic research (see, though, Berlin and Berlin 1975; Davies et al. 1992; Dougherty 1977; Kuschel and Monberg 1974; among others), as opposed to rapid survey work ${ }^{10}$ The present study was conducted in the context of an ongoing project in linguistic anthropology on Rossel Island, Papua New Guinea." The inhabitants of Rossel speak a language isolate, known variously as Yéli Dnye, literally "Rossel language," or Yele, Yela, Yelentye, or simply Rossel language, whose affiliation to any other languages has not been clearly established. There are somewhat over 3,500 inhabitants of Rossel, including one Australian missionary and some married-in native speakers of Austronesian languages (especially the languages of Sudest, Misima, and Nimowa). Yélî Dnye is the single predominant language, although many younger people also know a considerable amount of English through schooling or outside employment. Rossel, though, is a remote island surrounded by difficult seas, served by few vessels and no air strip, and is quite isolated. Previous published work on Rossel Island language is confined to a word list (Henderson and Henderson 1987), and the brief but invaluable grammar by Henderson (1995), whose practical orthography is used here. Although surrounded by Austronesian languages, Yélî Dnye shows little evidence of influence by them, and with its huge phoneme inventory and complex grammar is scarcely ever mastered by outsiders.

There are some reasons to think that the Yélî color expressions may be of special interest. First, they are somewhat dubious "basic color words," all being complex expressions, and in all but perhaps one case referring to objects with canonical hues. Second, ethnographic observation reveals little interest in color: there is no current artwork or handiwork in color, with the exception of baskets woven with patterns (usually natural versus black/blue). ${ }^{12}$ There is a keen interest in the multidenominational shell money, but color is an unreliable clue to the denominational values, and there is no special descriptive vocabulary. Third, the Yéli pattern of derived expressions with primary metaphorical reference, and the low salience of the entire system, may not be an isolated pattern, but rather one with similarities to others in Australia and New Guinea and perhaps elsewhere.

\section{Linguistic Analysis of Yélî Color Expressions}

Given the critiques of BCT theory above, it is essential to provide some detail about the linguistic properties of the local color terms. We need to know whether they are derived or basic, whether they are nominal or predicative, 
whether they come from a single form-class, and, if not, where the breaks in form-class occur.

Yélî (like perhaps most unwritten languages) has no superordinate word for "color." 13 One would not normally ask what color something is; to do so one would be forced to use the (noncolloquial) English loan color, as in "Ló kala?" [What color (is it)?], an innovation confined to those younger people who have spent time on the mainland. Instead, one would normally ask, "U pââ ló nté?" [Its body, what is it like? or Its body, how does it seem?], which could ask for any perceivable quality such as size or taste (the same difficulties in eliciting precisely color words were noted by Conklin [1955:341 n.] for Hanunóo). ${ }^{14}$ The question phrase ló nté, which also functions to mean "how?" is made up of the question marker ló and the word nté 'like' used to mark comparisons or similes: it could therefore be thought of as requesting a simile or comparison as an answer. ${ }^{15}$

The absence of a superordinate is accompanied by the absence of any clear subordinate terms or hyponyms under the color expressions that do exist (the best candidate is a term that might be glossed "dark-red" but is used in contrast to expressions referring to focal Red). The lack of any taxonomic structure makes it hard to be sure what the boundaries of a lexical field are; this then makes it difficult to investigate the relevant lexical set independent of an imported set of stimuli, as critics of BCT theory have pointed out.

\section{Reduplicated Nominals}

We thus turn to discourse to look for expressions used to refer to hues. In reference to colors, there seem to be two major classes of expression. The first class is formed by reduplication of nominals:

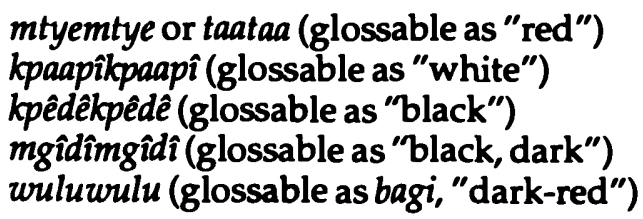

These are all reduplications of names of objects:

1. mtye, or taa, 'red parrot species' (these two forms are said to mark minor dialect differences along the northern coast, but in fact some informants use both);

2. kpaapî' 'white cockatoo';

3. kpêdê 'tree species, yielding valuable nut';

4. mgidî'night'; and

5. wulu 'juice, sap, spit'.

The color reference of the reduplicated terms mtyemtye (or taataa) and kpaapikpaapî is obviously derived from the nominal reference: the red parrot is a startling crimson and the white cockatoo a pure white apart from its sulfur comb. The "black" term is more opaque: the kpedle tree has a brown 
bark and wood, and (as pointed out by an informant) its nuts are not black until they are roasted in the fire as part of the procedure required to render them edible. 16 The other "black, dark" term, mgidimgidî, is derived from the word for "night, darkness" (as in mgidî vy:o 'in the night/dark'); mgidîmgidî is the normal description for dark (e.g., "Kpomo u mênê ghi mgidîmgîdî" [Cave, its inside parts dark, i.e., Deep in the cave it is dark]). ${ }^{17}$ The "dark-red" expression has a different semantic status, in that the reduplicated form has primary nominal reference to the Kula-valuable known to the Massim as bagi, which is manufactured on Rossel even though the island is not part of the Kula ring (the origin of the Rossel term is obscure-it may be derived from t:aa wulu betel juice').

This class of color expressions is formed by a general, semiproductive rule for deriving adjectives from nouns by reduplication-it is notable that the color expressions above do not belong to the set of adjectival roots in the language (which cover notions of size, as in ndîi 'big'; quality, as in dono 'bad'; and state, as in kuu 'raw, unripe'). Thus we have the following terms for describing taste, derived from appropriate nouns:

<1> mty:aamty:aa 'sweet' - from mty:aa 'honey'

$<2>$ nj.iinj.ii 'sweet, salty, spiced'-perhaps from nj:ii a tree species' or, more likely, ntii'salt water'

$<3>$ kinikini 'greasy'-from kini 'fat'

<4> 'nuwó' nuwó 'bitter, sour'-from 'nuwó 'point'

The color expressions mtyemtye, kpêdêkpêdê, and kpaapîkpaapî clearly are parallel to these taste terms rather than to basic adjective roots like ndî ' big'. $^{\prime}$

The syntax of these and other modifier expressions is relevant to their status as color terms. For example, Lyons (1999) claims that "first-order" emergent color terms that lack context-independent, abstract reference to hue might have primarily predicative uses, rather than nominal uses associated with "second-order" abstraction. Therefore it is important to know whether the Yélî reduplicated terms are essentially adjectival or nominal. Although there are clear tests for adjective roots (Henderson 1995:67, 76), nominal and adjectival classes also overlap in both semantic oppositions (the antonym of, for example, kuu 'raw, unripe' is kigha 'ripe fruit, ready for eating', which is arguably a classificatory noun) and syntactic potential (e.g., both can occur as verbless predications). But a useful distinguishing test is that in noun-noun compound phrases, the modifying noun precedes the head noun (as do deverbal gerunds), while in noun-adjective phrases the modifier follows the head. Using this test, the reduplicated nominals used for color reference have adjectival status: one says pi kpêdêtpêtê 'man black' for "black man," not the other way around.

These derived adjectives thus occur inside NPs of the form [ [Determiners] [Head N] [Classifier Nominal] [Adjectival Phrase] ],,$^{18}$ as, for example, in the following:

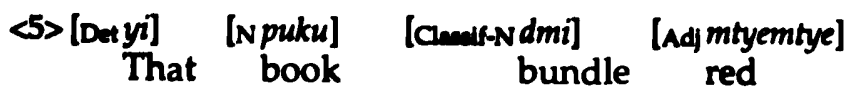


This phrase is structurally ambiguous between the attributive reading indicated, a complex NP, and a predicative reading where the phrase constitutes a simple clause (i.e., between "that red book" and "that book is red"). However the predicate reading of the adjective is discouraged unless the head-noun denotes a surface or physical property. Thus, rather than saying, "The man is white," in Rossel one would prefer, "The man's skin is white." Hence many such expressions have both a compound nominal (or a double compound as illustrated here) and a following adjectival phrase:

$$
\begin{aligned}
& <6>\text { [[Mod-N [Mod-N nkéli] [Head-N pi]] [Head-N [N too] } \\
& \text { Boat man skin }
\end{aligned}
$$

[Class-N pee] ]\} [Adj kpaapikpaapî]

'Europeans have white skin.'

The role played by pee'skin' here is in the default case played by the nominal pâa 'body, surface, external properties'. Thus, one asks,

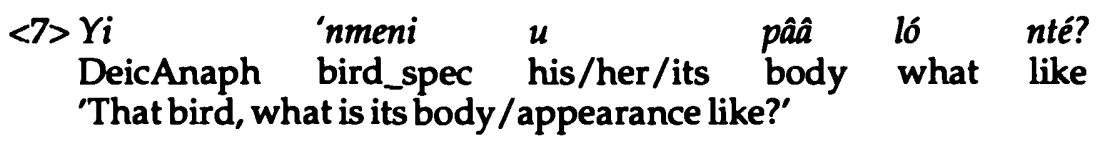

And one get the answer,

$$
\begin{aligned}
& <8>u \text { pâa kpaapîkpaapî } \\
& \text { its body white } \\
& \text { 'It is white in appearance.' }
\end{aligned}
$$

Even in elliptical answers to questions, the $u$ pâa phrase is normally preserved. Colors are thus not colloquially predicated of objects but, rather, of the relevant surfaces of objects. This insistence on exactitude, bordering on philosophical pedantry, is striking. Perhaps the explanation is that a color term like kpaapîkpaapî still has analogical reference to kpaapî (white-parrot), and the specification that it is a surface property that underlies the similarity serves to restrict the interpretation toward the color meaning. ${ }^{19}$

\section{Descriptive Phrases}

Another kind of phrase with color reference is exemplified by yi kuu yâa, literally "tree raw/uncooked leaf," that is, fresh young leaves (the exact meaning of $k u u$ will exercise us below). As with the reduplicated terms, the whole descriptive color-indicating phrase normally follows the nominal being modified, but unlike the reduplicated expressions some informants also allow the descriptive phrase to precede the noun as below, suggesting that the descriptive phrase (unlike the reduplicated forms above) may be interpreted as a modifying compound nominal: ${ }^{20}$

$$
\begin{array}{lll}
<9>\text { mu yi } \quad \text { kuu } & \text { yda } & \text { puku } \\
\text { that tree raw/unripe leaf/roof book } & \text { lat } \\
\text { 'That green book' } &
\end{array}
$$


The internal structure of the phrase yi kuu yâa 'tree fresh leaves' suggests that it has an idiomatic status with an adjective kuu between two nominals, and specifically with the adjective unusually before the modified noun yââ 'leaves'. One could also say, for example, that one is setting off in search of $y i$ yâa $k u u$ 'tree leaves raw/uncooked', but this is less likely to suggest a primarily coloric interpretation. This is a productive pattern, and other phrases with color reference take the same word order, for example, k:ii chii yâa 'banana desiccating leaves', which may be used as a way of designating yellow. Phrases of this type, mostly after the head noun, function as color-referring adjectives, but they are clearly descriptive phrases, unlimited in principle. In contrast to the reduplicated forms, these descriptive phrases are often marked as explicit similes. Thus, contrast the following:

<10> puku dmi kpêdêkpêdê a ka
book bundle black my GOAL/SOURCE DEICproxS give
'Give me the blackbook.'

<11> puku dmi káámi kîgha kii a ka
book bundle nut type ripe just_like my GOAL/SOURCE DEICproxS give
'Give me the book (colored) like the fruit of the Káámi tree.'

The reduplicated color expressions only take explicit markers of simile when an approximation is being indicated (as in "like red, but not really red"), but all other color-indicating expressions routinely co-occur with them. The explicit markers of simile, nté 'like', ntee tpile 'thing like this', $k: i i$ 'similar to', and myenté 'same as', occur after the color-exemplar description, for example, ngomo nugu ghi ntee tpile Ngomo-nugu Reef area like that'. It is worth pointing out that some theorists think that a notion of comparison is basic to all color words (q.v. Wierzbicka 1996: ch. 10; Wittgenstein 1958). Moreover in some languages the general word for "color" is related to the word for "like" (Evans 1992:107), and in others a "looks like" suffix accompanies many color expressions (Berlin and Kay 1991:38). ${ }^{21}$ These are clearly signs of the emergence of color vocabularies from the names of objects that exhibit the relevant hue. ${ }^{22}$

By the structure of their expressions, yi kuu yââ and yi chii yââ are clearly contrastive ("tree unripe leaf" versus "tree desiccating leaf"). They serve generally to pick out green and yellow hues respectively. The adjective kuu indicates unripe (of fruit), raw or uncooked (of food), innocent (of people), and, in the collocation with the word for leaves, fairly clearly denotes fresh, new leaves (see Derrig 1978 for cross-linguistic patterns in this association chain). One informant insisted that a dried but still green leaf could not be described with kuu. (The succulence association, much reported for green descriptors, is less salient in English-but note green sapling. Otherwise there is a rather striking similarity between kuu and the metaphorical range of English green: cf. green apple, green freshman, and so forth.)

The adjective chii (sometimes tii) ${ }^{23}$ indicates drying, desiccating, withering but not yet dead, and is especially used of vegetation. Some people preferred the expression k:ii chii yal 'banana desiccating leaf', for now the exemplar is both familiar and restricted. (One subject gave orange and brown ranges 
in the WCS task for yi chii yâa, reserving the phrase kii kigha nt:u 'ripe banana' for yellow, and most subjects agreed in elicitation that it could have extensions right into red.) The reference to the natural process of drying out was made rather plain by remarks such as, "This chip [D8] is rather too old to be chii [drying], it is ntóó [dead]." The underlying dimension here of wet/succulent/green versus dry/brittle/yellow is very reminiscent of the celebrated opposition described by Conklin (1955) for Hanunóo. The Hanunóo case raises the question as to the extent to which expressions used to denote hues really are essentially color terms at all. Lyons $(1995: 220,1999)$ has revived interest in this opposition by pointing out that ancient Greek khloros clearly meant "fresh, unripe, moist" as well as "green," and for this reason could cover yellow fruits and the like. Kay (1999) suggests that we are simply dealing here with polysemy, but the cross-cultural systematicity of this particular pattern almost certainly has another source: a simile or metaphor rarely picks up just one property of the metaphorical referent, and, insofar as such descriptive phrases retain transparency, they are likely to retain multiple levels of meaning.

Of all the metaphorical descriptive phrases, yi kuu yâa 'tree fresh leaves' turned out to be the most consistently used in color elicitation tasks. It is therefore worth noting that even this idiomatic expression often occurs with a marker of explicit simile, for example, yi kuu yââ ntee tpile 'tree fresh leaves like that thing'. The yellow descriptors were much more variable than the green ones, substituting the leaves of other plants for yi 'trees', especially palms like the banana and coconut (e.g., k:ii chii yââ banana desiccating leaves'), or substituting another simile, like the ripe fruit of the banana (kii kigha nt: $u$ 'banana ripe fruit'). The latter brings out another opposition to kuu 'raw, unripe', in kigha 'ripened fruit'. Thus, these metaphorical expressions do in certain ways act like a structured semantic field, one informant opposing both k.ii kîgha nt:u 'ripened banana fruit' (yellow) and yi chii yââ 'drying leaf' (orange) to kuu 'unripe, fresh'.

In discourse, terms for blue hardly seem to occur. In the various artificial tasks described below, descriptors for blues were particularly variable, and not all subjects attempted any descriptors for hues in this area. The standard reference however is clearly to the fruiting body káami kagha, which contains a culturally important edible nut. When ripe it is a deep purple-blue, which explains why some subjects asked to identify the focus of this color on a Munsell chart located the focal as dark as I27 or I29 (a deep navy) or I31 (a deep purple-blue). Different kinds of sea area were also invoked, with sometimes an opposition between ntii, the deep sea, focused near our focal blue (G29) versus chênê, the reef passages (light blue) focused as light as C28. Or ntii might be focused on $\mathrm{G} 30$ and opposed to kámi kigha focused on 129. A simile based on the sky was also used (mbor ntee 'like the sky', focus F29). The question of the focus of metaphorical categories will concem us below. ${ }^{24}$

Many ethnographic studies of color expressions report domain-specialized or contextualized color terminology, for example, names of color patterns for cattle (Davies et al. 1992; Fukui 1996; cf. our roan, pinto, piebald of horses) or names for colors of states of vegetation of specific genera (Kuschel 
and Monberg 1974). There does not seem to be any such specialized terminology on Rossel, despite the existence of an elaborate shell money system, whose 18 denominations are distinguished largely by color/pattem oppositions. This accords with the general impression that surface color is not of any communicational import in this speech community, even in specialist areas.

\section{Modifying or "Hedging" Color Expressions}

In the tasks to be described below, many modifiers were used, meaning variously "somewhat," "light," "not really," and so forth. Favorite modifiers were pee tp:00 X 'piece child/small, that is, a bit $X^{\prime}$ ', and daa d:uud:uu mbiy:e $X$ 'not entirely $X$ '. The details are discussed below. Here I merely wish to point out that such modifiers are truth-functional operators, just as English It is light blue entails that it is blue, but It is not really blue entails (at least without heavy stress on blue) that it is not blue. It is somewhat blue, on the other hand, may entail that it is blue, but in the peripheral membership of that category, that is, it is an operator on fuzzy set membership. These are fine discriminations, of a kind difficult to make in an exotic language, but making an accurate map of referential range will depend on just such discriminations. In addition, questions arise as to whether, in a study of BCTs, we can count an instance of light red as a modified BCT, or by virtue of its multiword composition, as having jettisoned its BCT status for the purpose of term mappings. Clearly, phrases of the kind "really $X$ " might be crucial to a theory of focality; below I draw attention to the fact that the colors denoted by "really $X$ " phrases do not coincide with focal colors obtained on a color chart, perhaps for two reasons: (1) in similes or descriptive phrases, the exemplar object is likely to draw canonical reference away from the psychophysically salient focus on the chart, (2) focality on the chart may be in part a neighborhood effect. (For general methodological advantages derivable from the study of color term modifiers, where their meaning is clear, see Burgess et al. 1985.)

Let me summarize so far. Yélî expressions with color reference occur in adjectival constructions, either (normally) following the head noun as modifiers or at the end of clause as predications. They are of two types, both derived stems, which may be distinguished on distributional and structural grounds: (1) reduplications of nominals (the various terms for "white," "black," "red," and "dark-red"); and (2) phrasal descriptions and similes (with reference to all other hues). Both types make reference, in their form, to prototypical objects that exhibit the colors in questions. There is no distributional argument that either of these types form an exclusive word class restricted to colors-type 1 is identical in form to, for example, the adjectives describing basic tastes, and type 2 to other similes and metaphors. In the absence of a superordinate word for "color," no semantic criteria based on sense relations will serve to pick out a class of color terms. 


\section{How Many "Basic Color Terms" in Yélî?}

The classification of the Yélî terms as BCTs or otherwise is not straightforward. On semantic grounds, we would want to make distinctions between the following categories: ${ }^{25}$

1. expressions whose sense contains no essential reference to color, for example, yi kuu yââ 'tree fresh leaves', but which can be used to denote (or at least connote) colors;

2. expressions whose sense arguably incorporates coloric information, for example, mgîdîmgîdî 'dark-dark, night-night', but which would not normally be thought of as just color terms (and are therefore not good candidates for BCTs);

3. expressions whose coloric information exhausts their sense, and are therefore good candidates for BCTs-the best Rossel exemplar here is the reduplication used to denote black.

\section{Consider the criteria originally suggested by Berlin and Kay: ${ }^{26}$}

Ideally, each basic color term should exhibit the following four characteristics:

(i) It is monolexemic; that is, its meaning is not predictable from the meaning of its parts.

(ii) Its signification is not included in that of any other color term.

(iii) Its application must not be restricted to a narrow class of objects.

(iv) It must be psychologically salient for informants. Indices of psychological salience include, among others, (1) a tendency to occur at the beginning of elicited lists of color terms, (2) stability of reference across informants, and (3) occurrence in the idiolects of all informants. [1991:6-7]

They go on to add that, in doubtful cases,

(v) The doubtful form should have the same distributional potential as the previously established basic terms.

(vi) Color terms that are also the name of an object characteristically having that color are suspect. This subsidiary criterion would exclude "orange" in English if it were a doubtful case on the basic criteria (i-iv).

(vii) Recent foreign loan words may be suspect.

(viii) In cases where lexemic status is difficult to assess (see criterion [i]]), morphological complexity is given some weight as a secondary criterion. [1991:6-7]

Note that criterion iv, which is crucial here, is a psychological, not a linguistic, criterion. ${ }^{2}$ If we apply these criteria to the Yéli expressions in Table 2 , we may be in serious doubt as to whether there are any BCTs in the language. Let us examine how the Yéli terms fare by each of the criteria. Frist, the terms are not simplex morphemes, being either reduplications of nominals or much more complex phrases, but the reduplicated terms are the best candidates for monolexemic status. By phonological criteria, the reduplications cannot be considered monolexemic (if they were, the second $k p$ in kpêdêkpêdê would be voiced, for example). But the semantic criterion, that the meaning of the whole should not be predictable from the meaning of the parts, guides us less clearly with the reduplicated terms. We have to consider the nature of reduplication in Yéli. 
Table 2

Expressions used to denote colors in color naming tasks.

\begin{tabular}{|c|c|c|}
\hline Term & Gloss & Reference \\
\hline 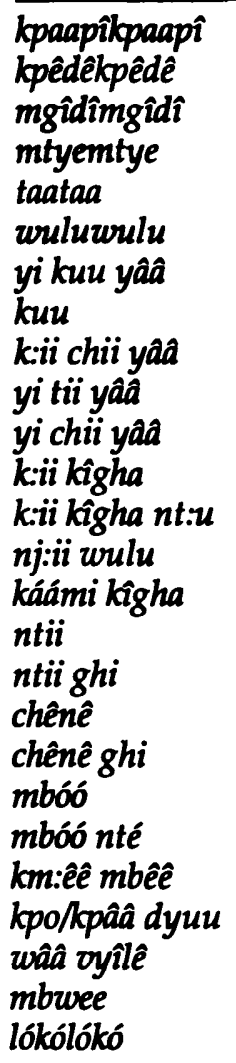 & $\begin{array}{l}\text { 'white cockatoo REDUP' } \\
\text { 'tree-species REDUP' } \\
\text { 'night REDUP' } \\
\text { 'red parrot REDUP' } \\
\text { 'red parrot REDUP' } \\
\text { 'juice REDUP' } \\
\text { 'tree unripe/fresh/uncooked leaves' } \\
\text { 'unripe/fresh/uncooked' (1 subject) } \\
\text { 'banana desiccating leaves' } \\
\text { 'tree sand/dry leaves' } \\
\text { 'tree desiccating leaves' } \\
\text { 'banana ripe' } \\
\text { 'banana ripe fruit' } \\
\text { 'sap of nj:ii tree' } \\
\text { 'nut species fruit' } \\
\text { '(deep) sea' } \\
\text { 'deep sea area', 'rainbow' } \\
\text { 'water in reef passage' } \\
\text { 'area of water in reef passage' } \\
\text { 'sky' } \\
\text { 'like the sky' } \\
\text { 'stone landslide' } \\
\text { 'pile of ashes' } \\
\text { 'faded, worn out' } \\
\text { 'old, rotten' } \\
\text { 'luminous' (<lókó 'luminous mushroom') }\end{array}$ & $\begin{array}{l}\text { white } \\
\text { black } \\
\text { black, dark } \\
\text { red } \\
\text { red } \\
\text { bagi, dark red } \\
\text { green } \\
\text { green } \\
\text { yellow } \\
\text { yellow } \\
\text { yellow } \\
\text { yellow } \\
\text { yellow } \\
\text { orange } \\
\text { dark blue } \\
\text { blue } \\
\text { blue } \\
\text { light blue } \\
\text { light blue } \\
\text { blue } \\
\text { blue } \\
\text { brown } \\
\text { grey } \\
\text { var. transitional hues } \\
\text { var. dark hues } \\
\text { bright colours }\end{array}$ \\
\hline
\end{tabular}

Take kpaapikpaapi: is the meaning ("white") predictable from the meaning of the parts (kpaapi, white cockatoo)? Yélî uses reduplication frequently in word formation: for example, verb stems are reduplicated for durative aspect, adverbial phrases are derived from reduplicated nominals (often with adverbializer mbiy:e or ngê, like lîmîlîmî ngê, quickly, from lîmî, lightning), adjectives are intensified by reduplication (mb:aa 'good', mb:aamb:aa 'very good'). But the derived meanings are often at least partially opaque, as so often in derivation (mgee 'rotten [of fruit]', mgeemgee 'lazy'). We have already seen that there is a regular process that derives adjectives from nouns by reduplication, where the adjective picks out a salient property of the noun (as in mty:aamty:aa 'sweet' from mty:aa 'honey'). Kpaapikpaapi fits this pattern: the reduplication transparently suggests its meaning, although it is conceivable that it might have designated some other salient property of white cockatoos (like their loud screech). Kpêdêkpêdê 'black' more clearly satisfies criterion (i) because its semantic relation to kpêde 'tree species' is less clear. On the other hand, the alternate term for "black," mgidimgidi 'dark-dark, 
night-night', is more transparent. The red expressions are as semantically transparent as the white expression.

Were we to be in doubt, and thus to invoke the secondary criteria (viii), morphological simplicity, and (vi), which makes terms that are also the names of objects suspect, we would probably conclude that Yéli has no basic color terms. ${ }^{28}$ The point is of some importance because I suspect that many color expressions in Australian and Papuan languages, and Austronesian languages in contact with them, utilize color expressions derived by reduplication from nominals referring to objects with canonical colors. ${ }^{29}$ The BCT status of such terms surely requires careful linguistic analysis as well as referential evidence.

Suppose, for the sake of argument, we grant that the "white" and "black" terms pass criterion $i$. Then there is little doubt that they also pass ii and iii. Now we will probably make the same decision for the red terms, but already there are a couple of points to note. First, there are two terms in common parlance, mtyemtye and taataa. As noted, these are, at least in folk theory, associated with the eastern and western dialects respectively. Now, in the eastern dialect the word for red parrot is mtye, and in the western it is taa. That there are two red terms based on the variant parrot terms suggests that the reference to the bird is still salient, that these are partially live rather than fully dead metaphors. Second, despite the dialectal association, many consultants use both forms, and a few made a different use of them in color-naming tasks, locating distinct foci, for example. Third, there is yet another term, wuluwulu, which some consultants used to distinguish darkred, squeezing the reference of the other terms into the lighter shades. Wulu refers to juice or sap (including the red betel juice frequently expectorated), but the reduplication wuluwulu also has primary reference to another object, namely, to bagi, the dark-red shell necklace Kula valuable that Rossel islanders make and export. In this case, reference to color may be doubly indirect. Wuluwulu, which is used to denote dark-red, might be thought to run afoul of criterion $\mathrm{ii}$, in that it might be thought a hyponym of one of the other red terms; but subjects who used it in the WCS naming task systematically reserved it for appropriate dark-reds, and none could be persuaded to call wuluwulu a kind of mtyemtye or taataa.

Thus when we come to criterion iv, psychological saliency, there is a significant difference between the "white" and "black" terms, on the one hand, and the "red" terms, on the other: kpaapikpaapî and kpêdelkpêdê are more likely to be elicited first, and are more stable in both reference and linguistic form than the competing red terms. Still, it is fairly clear (based on the treatment of examples presented in Kay et al. 1997) that in the WCS tradition Yéli would be considered to have these three basic color words: kpaapikpaapi, kpêdelkpedê, and mtyemtye (or taataa). If that is all the basic color words that Yéli has (and the rest, except for the dark-red expression, are indeed complex phrases and similes), it would count as a Stage 2 system. We will return to criterion iv when we consider the results of the naming tasks, which allow some inferences about psychological saliency from consistency and variability in use. 


\section{Terms Used in Color-Naming Tasks}

When using the procedures developed by Berlin and Kay and the WCS, many further expressions were elicited. Table 2 contains a list organized by reference to the corresponding English color words, and within that by frequency of use. In other elicitation or texts, quite a few further terms cropped up, for example, to denote yellow hues: njili nênê kuu Njili tree flower fresh' for yellow; kwodo-nkaa chii yala 'inedible-banana-species drying leaves', again for yellow; kêmkêm w:uu taa ntee tpile 'like the yolk of chicken egg'; tpê nênê ntee tpile like the flowers of the tpê tree'; ntéli wuli '(like) fruits of ntéli tree'; and so on.

For all but one of the subjects in the two tasks, all these expressions were sometimes further modified, especially with the phrases pee tp:00 'somewhat, a bit, a little' and diuudiuu mbiy:e 'completely' or ndêndê 'truly'. It is worth remarking that subjects considered that, if a color patch could be described as pee tp:00 $X$ (where $X$ is an expression with color reference, and pee tp:00 literally glosses as "piece little/child"), then this implied or implicated that it was not $X$ (perhaps more strongly than English greenish or a bit green implicate that the referent is not green). Thus, one subject glossed pee tp:00 kpêdêkpêdê 'a bit black' as kpêdêkpểê ntee, ngmênê daa kpêdêkpêdê 'like black but not black'. In the coding of responses to the WCS task this puts us in a bit of a dilemma, as to whether to count pee tp:00 $X$ as in the (peripheral) extension of $X$ or not (I have in fact counted them in because of the very restricted extensions of most of the expressions, see below, but I have done so with misgivings).

Sometimes they referred to a color patch as, for example, daa diuudiuu mbiy:e mtyemtye 'not completely/really red', implying a darker hue. One inventive informant $(J)$ utilized a number of further modifiers: he opposed the term kuu 'unripe/raw' with reference to deep hues (e.g., with application to ntii ghi to mean "deep blue") to kigha 'ripe' with reference to light hues. He further used the unreduplicated kpaapi (from kpaapikpaapî 'white') to refer to light colors, for example, chênê ghi kpaapi 'whitish reef-entrance parts', that is, light blue (explaining that the unreduplicated form was unlikely to be misunderstood in this context but could as well be reduplicated). But unlike what the English gloss suggests, he insisted that X kpaapi light/white $X^{\prime}$ implied that the chip in question was not $X$. Similarly, $X$ kpêdelppêdê 'dark/black X' was used to indicate "darker than X." In fact, he offered the implication kuu kpaapi, daa d:uud:uu mbiy:e kuu 'white green, thus not completely/really green', which does indeed suggest that both imply that the chip in question is outside the range of kuu.

More interesting than the inevitably problematic fringes of color categories are the modifiers indicating focal members, here especially diuud:uu mbiy:e $X$ 'really $X$ '. Subject E, for example, restricted his "really greens" to bluer, darker greens than those he pointed to on the Berlin and Kay chart as focal greens. Using the chart, on a first estimate he gave G17, on a second H18-19-20. The implicit foci judged by modifier usage were G21, H20-21-22, 21, that is, much darker values. Similarly, subject $M$ gave a chart focus of H18, but gave implicit foci at I16 (darker) and H17 (lighter). Subject J, who 
gave Berlin and Kay focals at F19 or G19, used only one such "really green" expression, for I18 (darker). These greens at the I-level are truly dark, blackish greens (indeed marginal greens in English) and contrast markedly with the "universal focus" (or cross-linguistic average) of Heider (1971), focused on F19. Outside the context of the chart, the literal reference of the simile to rain forest tree foliage seems to bring the foci down to much darker canonical exemplars that we would think of as good greens. This phenomenon does raise serious questions about how the chart may bias responses toward light exemplars, away from boundaries with other hues.

The list in Table 2 conveys the variability, the fresh inventiveness of metaphorical descriptive label, which clearly characterizes most of these expressions. Many of them were used with an explicit marker of simile, ntee 'like' and $k: i i$ 'same as', as in:

\section{<12>k:ii Yélîngêp p:uu paint n:ii a t:a káámi kîgha just_like BoatName on paint that_one CLOSE hanging nut fruit 'The paint adhering to the (boat) Yélîngep is just like the ripe Káámi nut' (i.e., it is dark blue)}

Some of the expressions above (e.g., mbón ntee 'like the sky') would only occur with this explicit marker of simile, at least outside a context that allows elliptical reference to earlier full usages.

Nearly all of these expressions will fail Berlin and Kay's criterion iv, psychological salience, for BCT status as well as other criteria. The only partial exception is the "green" phrase yi kuu yâa. Although this is basically a descriptive phrase rather than a dedicated color term, it does have a greater psychological salience than any of the other expressions on this list: it was used by most subjects on the WCS task and has fewer alternative expressions. Despite its multilexemic phrasal status and its potential occurrence before rather than after the modified noun, it might be considered an incipient "green" term by Berlin and Kay. ${ }^{30}$

It should be noted that there are a number of other phrases with color reference about which I shall have little to say because they do not denote single hues. For example, there are terms for "bunting" (e.g., tingêtangê 'two colored'), used to refer to multicolored objects. Incidentally, Kay and McDaniel (1978:622) suggest that compound expressions of the kind yellowish green, blue-green "are found in all languages" to indicate degrees of membership in a category; but in Rossel language compounds of this kind indicate bunting, not blends or intermediate hues (see also the suggestion in Lyons 1995:203 that the possibility of such blends depends on the language-specific structure of color space). Degrees of membership are instead indicated by modifiers of the kind already discussed, for example, pee tp:00 'a bit, somewhat, almost' and d:uud:uu mbiy:e 'really, intensely'. We shall return to the issue of the isolation of BCTs in Rossel in the final sections, after describing the evidence for psychological saliency. 


\section{Color Reference in Color-Naming Tasks}

Two kinds of color-naming tasks were employed. One was the classic Berlin and Kay procedure, where a subject is shown an array of 330 Munsell chips on a single chart and asked to point to best and all exemplars of each of a previously elicited set of terms. ${ }^{31}$ The other task was the WCS procedure, following the instructions and using the stimuli kindly provided by Robert MacLaury, which consists of the presentation and naming of individual color chips in random order. ${ }^{32}$ These are rather different procedures in that, in the Berlin and Kay task, the subject provides a set of terms and then is asked to map their extensions with respect to each other on a complete color chart, while in the WCS task a subject is given, without prior elicitation, a succession of color chips one at a time, which must be named without simultaneous comparison with one another. In the latter task, no selection of "basic color terms" as opposed to other color-designating terms is done in advance. ${ }^{33}$

Seven subjects completed the WCS task and subsequently did the Berlin and Kay task (here one subject I had to be replaced by another, Mu; see Table 3). In addition, two further males (ages 40 and 20) and one further woman (around 50) were also consulted as checks. They were all from the same dialect area and are all at least part-time subsistence farmers; however, $M$ also works as a mission employee, $B$ polishes shell valuables, and A does evangelical work. The sample is skewed toward higher education than the average inhabitant has-most Rossels have primary education at most (schooling is not compulsory)-and it also contains only one woman (her responses were informally checked with the 50-year-old woman). This is admittedly a poor sample by the standards of the WCS (with a standard of 25 mixed subjects). Unlike the WCS, however, a full standard test for color blindness and normal color vision was first administered to all subjects, namely Ishihara's tests for color deficiency (Ishihara 1996). All subjects proved to have normal full color vision. ${ }^{34}$

Table 3

Subjects.

\begin{tabular}{llllll}
\hline \hline ID & Sex & Age & Education & Outside Experience & English Competence \\
\hline B & m, & 65 ? & none & none & minimal \\
J & m, & 37 & primary & sailor 3 yrs; Moresby City 4 yrs. & good \\
E & m, & 39 & secondary & schooling on Sudest and Misima low \\
M & f, & 20 & secondary & schooling on mainland & good \\
R & m, & 55 & primary & c. 1 year saw mill, mainland & low \\
Y & m, & 39 & primary & visits to mainland & limited \\
A & m, & 27 & secondary & schooling, seminary, mainland & excellent \\
Mu m, & $65 ?$ & none & government employment Misima medium \\
\hline
\end{tabular}

This subject participated only in the B\&CK task. 


\section{The WCS Task}

Seven subjects completed this task, which took about two hours per person. Following the instructions kindly supplied by Robert MacLaury, no prior elicitation of color terms took place. I asked subjects to describe how each chip looked, following first impulse, and not to worry about colors that seemed difficult. The question frame was as follows:

<13>alani u pââ ló nté
This one, its body how like?
'How does this one seem?'

The pace was gently forced, so that all 330 chips could be got through in about two hours, and therefore under similar lighting conditions (mostly afternoon shade). They were displayed singly against the background of a dark wood table, removing objects of bright hue from the field of vision, so there were in effect no comparison hues. The responses were written directly into coding sheets. No subjects were comfortable doing the task, frequently expressing the sentiment that such and such an old man would have known how to describe this chip, and some were given to long hesitations that were, where necessary, cut short by proceeding to the next chip. ${ }^{35}$

Ignoring modifiers, the terms utilized by the seven subjects in the task are listed in Table 3 with a single initial (B, J, E, M, R, Y, A, Mu) indicating use by each subject. All subjects used kpaapikpaapî 'white', kpêdêkpêdê 'black', and taataa 'red' (despite the fact that the last term was said to belong to the neighboring dialect; all but one subject also used mtyemtye, the local dialect word). All subjects also used the phrase yi kuu yâa for some area of the green hues. Beyond that, the consensus rapidly breaks down. Seventeen expressions were used uniquely by a single subject.

A measure of consistency concerns how many subjects used only one term within what would be a single English hue (although we need to be careful here to distinguish consistent subdivisions of color space from mere vacillation in terminology). Here all subjects used only kpaapikpaapi for whites. All but one subject used only one term, namely kpêdelkpêdê, for blacks. For green hues, most subjects used only yi kuu yââ, but the term kuu was also employed by two subjects. But for other hue areas, most subjects used more than one term. For example, for red hues, most subjects used both mtyemtye and taataa (perhaps not systematically, see below). For yellow hues, a great range of expressions were employed, as indicated in Table 4, again mostly without systematic subdivision of color space, and similarly for blues.

Taken together, these facts suggest that only a handful of expressions are the conventional expressions for a perceptually salient hue: loparpilparapi 'white', kpêdêkpêdê 'black', with mtyemtye and taataa vying for "reds" and the phrase yi kuu yâa predominantly chosen for "green." For yellow hues, for example, some single subjects used many expressions, and there was clearly no consensus, while for blue some subjects offered no expressions at all. Let us call this varying degree of fixedness of expression a cline of conventionalization. Now the reader will note that this order of conventionalization, 
Table 4

Color expressions used by particular subjects in the WCS task.

\begin{tabular}{|c|c|c|c|}
\hline Term & Gloss & Reference & Used By: \\
\hline 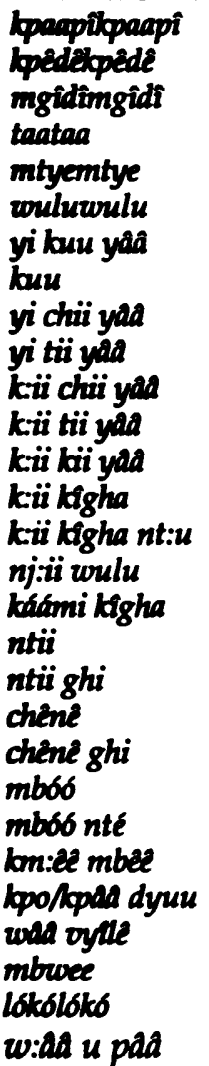 & $\begin{array}{l}\text { 'white (cockatoo)' } \\
\text { 'black (nut)' } \\
\text { 'night-night' } \\
\text { 'red (parrot)' } \\
\text { 'red (parrot)' } \\
\text { 'dark red (bagi)' } \\
\text { 'tree unripe/fresh/uncooked leaves' } \\
\text { 'unripe/fresh/uncooked' (1 subject) } \\
\text { 'tree desiccating leaves' } \\
\text { 'tree sand/dry leaves' } \\
\text { 'banana desiccating leaves' } \\
\text { 'ditto' } \\
\text { 'ditto' } \\
\text { 'banana ripe/fruit' } \\
\text { 'banana ripe/fruit fruit' } \\
\text { 'sap of nj:ii tree' } \\
\text { 'nut species ripe/fruit' } \\
\text { '(deeep) sea' } \\
\text { 'deep sea area', 'rainbow' } \\
\text { 'water in reef passage' } \\
\text { 'area of water in reef passage' } \\
\text { 'sky' } \\
\text { 'like the sky' } \\
\text { 'stone landslide' } \\
\text { 'pile of ashes' } \\
\text { 'faded, worn out' } \\
\text { 'old, rotten' } \\
\text { 'luminous' (luminous mushroom loko ) } \\
\text { 'dog's body' }\end{array}$ & $\begin{array}{l}\text { whites } \\
\text { black } \\
\text { black, dark } \\
\text { red } \\
\text { red } \\
\text { dark red } \\
\text { green } \\
\text { green } \\
\text { yellow } \\
\text { yellow } \\
\text { yellow } \\
\text { yellow } \\
\text { yellow } \\
\text { yellow } \\
\text { yellow } \\
\text { orange } \\
\text { dark blue } \\
\text { blue } \\
\text { blue } \\
\text { light blue } \\
\text { light blue } \\
\text { blue } \\
\text { blue } \\
\text { brown } \\
\text { grey } \\
\text { transitional } \\
\text { various dark } \\
\text { bright colours } \\
\text { brown }\end{array}$ & $\begin{array}{l}\text { B,J,E,M,R,Y,A } \\
\text { B,J,E,M,R,Y,A } \\
\text { R } \\
\text { B,J,E,M,R,Y,A } \\
\text { B,J,M,R,Y,A } \\
\text { Y,A } \\
\text { B,J,E,M,R,Y,A } \\
\text { J,R } \\
\text { B } \\
\text { B,R,A } \\
\text { B,J,E,Y } \\
\text { B } \\
\text { J } \\
\text { J,M } \\
\text { A } \\
\text { J } \\
\text { B,M,Y,R,A } \\
\text { JA } \\
\text { JA } \\
\text { J } \\
\text { J } \\
\text { M } \\
\text { M } \\
\text { B } \\
\text { A } \\
\text { R } \\
\text { J } \\
\text { A } \\
\text { M }\end{array}$ \\
\hline
\end{tabular}


namely, white $>$ black $>$ red $>$ green $>$ yellow $>$ blue, is exactly congruent with the predicted encodings of hues in the evolutionary theory of Berlin and Kay.

\section{Focal Hues}

Let us turn now to the reference in Munsell color space for these various expressions (linguists use a simplified reference system, with numbers 1-40 indicating distinct hues, and letters $\mathrm{A}-\mathrm{J}$ indicating the scale from light to dark variants). First, let us consider the focal colors, which were elicited by asking for best extensions of the names produced during the naming of the 330 randomized color chips. Subjects would not give different foci for all expressions, many of which they claimed to be synonymous (cf. the many yellow and blue descriptors above) or to have no clear focus (as, e.g., for wâa vyîle 'faded', for which B15 was given under pressure). First, the "white" and "black" terms had their foci in the pure white (row A of the color chart) and pure black (row J), respectively, for all subjects. The red terms mtyemtye and taataa were claimed by some subjects to be synonymous, focused around G2, with only two subjects (B and $A$ ) volunteering different foci for them both. Two subjects systematically used the term wuluwulu (which literally refers to bagi, the dark-red shell necklace manufactured on Rossel and traded in the Kula) for dark-red, and one volunteered a separate focus for it as opposed to mtyemtye, while one subject distinguished different foci for three "red" terms as indicated below. The green expression yi kuu yââ (sometimes reduced to $k u u$, with the same focus) was very variably focused from a light to dark-green. As mentioned above, another way to assess focal colors is to see where modifiers are employed: it was noticeable here that most subjects seemed to consider a dark-green to be d:uud:uu mbiy:e yi kuu yâa 'really/completely (the color of) fresh leaves', and indeed the leaves of yi 'trees, excluding palms' in dense tropical rain forest are quite dark glossy green. In short, it is likely that the literal meaning of yi kuu yâa 'fresh tree leaves' suggests a much darker focus than the perceptually brightest green. It is notable that the greater linguistic variability in "yellow" expressions was nevertheless matched with a greater consistency in focus. The different expressions referring to blue hues had systematically different foci, the focus of káami kigha being a very dark blue, as is indeed the literal referent of the expression, a wild blue-black fruit that contains a much valued nut kemel.

These results show rather clearly that there is a consensus for the foci of the "white" and "black" terms that is not reached for other terms. The red terms show a fair variability in focal reference, with some subjects considering the various terms to be opposed and even those who do not varying from foci in light orange (E4) to crimson (G1). The green expression is perhaps in tension between literal reference of the simile and perceptually most salient green, while the yellow hue area, which has the most linguistic variability, appears to have the clearest focal area (an exception was subject A, who opposed yi tii yada, focused on brown, to kii kigha nt:u, see below). Those six subjects who found expressions for blue hues sometimes opposed terms. Beyond these terms we are into idiosyncratic expressions with their 
Table 5

Focal referents for select expresions.

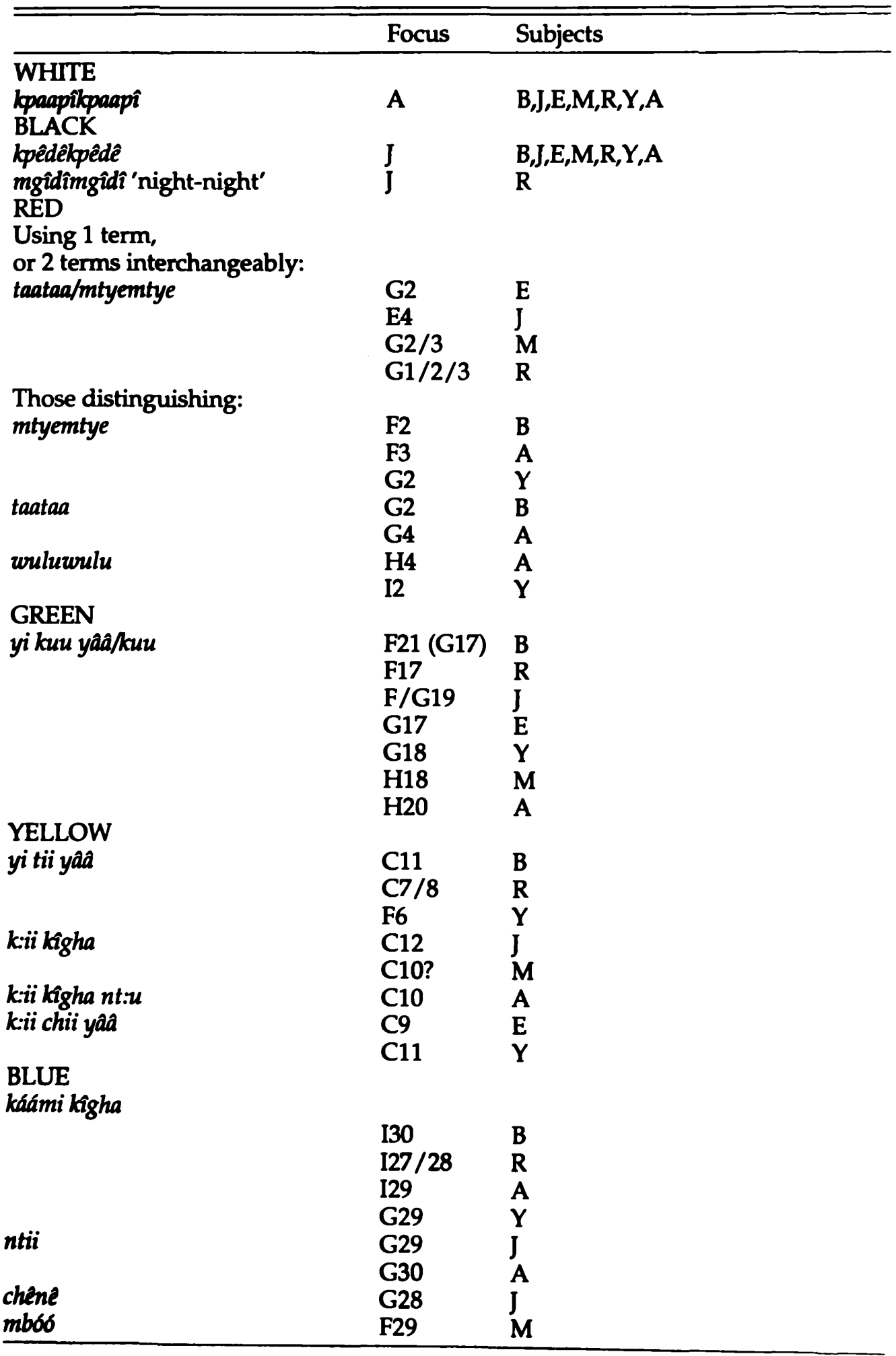


unique foci, for example, nj:ii wulu 'sap of Nj:ii tree, that is, orange' focused on D6 or kpo dyuu 'pile of ashes, that is, grey' focused on F0 (all of these terms used consistently, just as the English gloss suggests).

Berlin and Kay report that "it is rare that a category focus is displaced by more than two adjacent chips" (1991:13), with a mean difference of about one chip between speakers of the same language (1991:11). Although comparison of these foci with those published by Berlin and Kay (1991:8-9) for 20 languages shows that most of these foci are within or near the cross-linguistic range reported, yet the Rossel responses, apart from uniform "black" and "white" foci, appear to show a far wider intralinguistic spread than reported for other individual languages. For example, the Rossel red foci vary from $\mathrm{H} 4$ to $\mathrm{G} 1$ to $\mathrm{E} 4$, up to four chips apart; the $\mathrm{E} 4$ and $\mathrm{H} 4$ foci actually lie just outside the Berlin and Kay reported range for all languages. Similarly, yellow foci vary from C7-D9-C12, across almost the whole range reported by Berlin and Kay. The green foci are up to four chips apart, greater than the spread shown for Tzeltal grue, for example, and the H18 focus is outside the observed range. Most interestingly, the blue foci are spread from C28-I31, or seven chips apart diagonally, and half the foci are outside the reported range. The four within the range are foci belonging to three expressions, káámi kîgha, ntii, mbóó nté, and the three outside belong to káámi kigha 'dark blues' and chênê ghi 'light'. (Additional estimates of the foci were obtained during the Berlin and Kay task; the combined set is given in Figure 5 and is discussed below.)

From the point of view of BCT theory, these results are anomalous in the following respects:

1. If Rossel is a Stage 2 language (with White, Black, and Red terms), then the "black" and "red" terms should be composites, with variable foci, for "black" in Black, Green, or Blue and for "red" in Red or Yellow.

2. The variability of the focus for "red" is unexpectedly large while not including yellow.

3. The foci for all other color expressions deviate surprisingly from the "universal foci," that is, perceptual landmarks that might be expected to anchor even less conventionalized expressions.

My interpretation of these patterns is as follows. The "black" and "white" terms, the most conventionalized expressions, are just like our white and black terms - they simply do not fit the composite model for "early stage" color systems. The red terms are less conventionalized in usage: taataa and mtyemtye are variably interpreted as synonyms or as opposing terms with different foci, while the wuluwulu expression, with literal reference to the brown/dark-red bagi shells, is focused on H3 (dark-red) and H4 (darkbrown), perceptually removed from bright red. This last pattern holds for all the other terms: because they explicitly refer to exemplars, or objects that have a prototypical color, prototype reference is drawn away from the universal perceptual landmarks toward the color of the actual exemplars. The tension is especially clear in the variable foci of the "green" and "yellow" expressions. Further insight is provided where subjects modified these terms during the random presentation of chips, saying, for example, "really green" 
(d:uud:uu mbiy:e yi kuu yoâ, literally "completely tree raw/fresh leaves"): the chips so denoted are much darker green than Heider's (1971) universal landmark (and darker than the greens picked out as focal by the same subjects on the color chart). The literal reference is to dark tropical tree leaves (e.g., subject J gave only chip I18 this description, a chip two grades darker than the focus he picked out on the chart). Where we have competing kinds of exemplars, as in the various blue similes, the effect of this literal reference becomes manifest: káami is a nut with purple blue skin, pushing the reference to the darker, more purple border; chenê refers to the bright blue of shallow water over bright sand, pushing reference in the other extreme direction. Where subjects do not oppose such terms (i.e., they use only one "blue" term) they may nevertheless opt for a central blue focus, regardless of the metaphor employed. The effects of these idiosyncratic, self-invented oppositions on focal referents are also shown in the yellow color space: subject A opposed yi tii yôâ 'tree desiccated leaves' (centered on F6) to kiii kagha nt:u 'banana ripe fruit' (centered on C10), terms that were for many subjects treated as synonymous. Subject $A$ had in effect invented a sort of orange term. Another subject, J, opposed kii kîgha (focus at C12) to nj.ii wulu 'sap of the Nj:ii tree' (focused at D6), again a kind of orange term; the effect here seems to be to shift the foci toward the edges of the yellow and orange hues respectively.

This suggests that consensual color foci are not in fact a simple, direct reflex of perceptual salience. If they were, then one would expect metaphorical or nonce reference forms to unerringly have the same focus as stabilized, conventional forms. Rather, it seems that foci are partly a result of an emerged communicative consensus based on salience, as for example, proposed in Lewis's (1969) theory of convention. Before the number of terms has been fully established, and while metaphorical means are employed to denote specific colors, the focal referents are simply not uniquely determined. The Rossel system beyond the black and white terms, and certainly beyond the red ones, is apparently in this inchoate state. It appears to show that, rather than language passively reflecting a perceptual consensus, it takes active linguistic convention to forge a convention about focal reference (which, it is true, will tend to converge on perceptual salience, in this as in other domains).

\section{Category Boundaries}

The WCS procedure with its random presentation of colors is, in comparison with the Berlin and Kay task, which presents contiguous hues, a good "blind" test for conceptually coherent categories. In fact, when the subjects' usages of the expressions were mapped onto the color chart, the denotations of terms were generally found to form contiguous areas. One surprise was the reluctance to extend both the "white" and "black" terms, especially the latter. Table 6 gives an impression of the degree of extension simply by a count of chips named by a specific term; the number given includes modified terms like pee tp:00 kpaapikpaapi 'somewhat white', with the number of modified terms out of the total indicated. 
The very small extension of the kpêdêkpêdê term was surprising, given the absence of canonical blue and green terms, and subjects were pressed on dark greens and blues, but refused to use the "black" term. On the other hand, most subjects extended it to greys, so it seems that kpêdelppêdê has reference to hueless dark tones. The conservative extension is in marked contrast to, for example, the "green" expression yi kuu yâa, which for all subjects had the widest extension. ${ }^{36}$

Table 6

The numbers of chips covered by four specific expressions.

\begin{tabular}{|c|c|c|c|}
\hline Extension of Terms & No. of chips named & Modified & Subjects \\
\hline kpaapikpaapî 'white' & $\begin{array}{l}21 \\
29 \\
31 \\
17 \\
32 \\
30 \\
16\end{array}$ & $\begin{array}{r}7 \\
17\end{array}$ & $\begin{array}{l}\text { B } \\
\text { J } \\
\text { E } \\
\mathbf{M} \\
\mathbf{R} \\
\mathbf{Y} \\
\mathbf{A}\end{array}$ \\
\hline \multicolumn{4}{|l|}{ Mean $=25$ chips } \\
\hline kpêdêkpêdê 'black' & $\begin{array}{r}10 \\
16 \\
18 \\
9 \\
16 \\
12 \\
7\end{array}$ & $\begin{array}{c}5 \\
16 \\
4 \\
6^{*}\end{array}$ & $\begin{array}{l}\text { B } \\
\text { J } \\
\text { E } \\
\mathbf{M} \\
\mathbf{R} \\
\mathbf{Y} \\
\mathbf{A}\end{array}$ \\
\hline \multicolumn{4}{|l|}{ Mean $=13$ chips } \\
\hline taataa/mtyemtye** & $\begin{array}{r}30 \\
25 \\
35 \\
8 \\
8 \\
66 \\
13 \\
21\end{array}$ & $\begin{array}{r}12 \\
1 \\
24 \\
4 \\
5\end{array}$ & $\begin{array}{l}\text { B } \\
\text { J } \\
\text { E } \\
\text { M } \\
\text { R } \\
\text { Y } \\
\text { A }\end{array}$ \\
\hline \multicolumn{4}{|l|}{ Mean $=28$ chips } \\
\hline $\begin{array}{l}\text { yi kuu yâa } \\
\text { Mean }=65 \text { chips }\end{array}$ & $\begin{array}{l}45 \\
82 \\
70 \\
33 \\
72 \\
74 \\
81\end{array}$ & $\begin{array}{l}10 \\
16^{+* *} \\
57 \\
5 \\
2 \\
2\end{array}$ & $\begin{array}{l}\text { B } \\
\text { J } \\
\text { E } \\
\mathbf{M} \\
\mathbf{R} \\
\mathbf{Y} \\
\mathbf{A}\end{array}$ \\
\hline
\end{tabular}

"Five of these are the alternate term mgidimgidt.

"Use of one or both of these terms is included here, even though some subjects may have intended a contrast when both were used.

* This subject used kuu alone to label dark olive greens. 
Table 7

Unnamed areas of the WCS color space.

\begin{tabular}{ccc}
\hline \hline Subject & $\begin{array}{c}\text { Number of chips } \\
\text { with no description }\end{array}$ & $\begin{array}{c}\text { Number adjusted } \\
\text { for non-color descriptions }\end{array}$ \\
\hline J & 63 & 75 \\
A & 118 & 118 \\
B & 183 & 183 \\
E & 129 & 129 \\
M & 231 & 231 \\
R & 40 & 77 \\
Y & 94 & 94 \\
Mean & $123(38 \%)$ & $130(41 \%)$ \\
\hline
\end{tabular}

The size of the "red" area on the color chart was very variable, by a factor of eight times. Both the terms mtyemtye and taataa were employed, in noncontiguous patterns, by most subjects. But the third "red" term wuluwulu, if used, was used systematically to denote dark-red, occupying the lowest $\mathrm{H}$ and I rows of the chart. It then constricted the area for the other terms.

Although the table does not list all expressions used, it suggests that large areas of the color space are unnamed, and this is in fact so. The numbers and proportion of hue chips (the 320 chips with positive hue, not the grey scale) named is shown in Table 7. Figures in the right-hand column show corrected figures when names are eliminated that clearly are not restricted to a single contiguous part of the hue chart (e.g., mbwe 'rotten' or wââ vyillê 'faded').

As is clear, on average, about 40 percent of the entire color space is undescribed or unnamed in any way. At one extreme, one subject declined to name 72 percent of the chips, while at the other extreme, the most exhaustive namer still left 24 percent unnamed. It was evident during collection of the data that subjects strove to find a name where possible. Note that these figures include any kind of name, including expressions glossing "not really red," "somewhat like deep sea," and the like. The large areas of color space that are unnamed by Rossel people in the WCS task are even larger in the Berlin and Kay task.

This no-naming measure is an interesting degree of cross-linguistic variation not usually mentioned. However, it was already clear from appendix 1 in Berlin and Kay 1991 that speech communities probably vary in the extent to which terms are used to exhaustively cover the color space. Other studies confirm that there are systematic differences here: for example, 95 percent of 65 chips were named by English speakers, but only 25 percent of the same array by Setswana speakers (Davies and Corbett 1995:28; Davies et al. 1992:1077). The original Berlin and Kay hypothesis tacitly presumed "that every language contains a small set of words-the basic color terms-each of whose significatum is a color concept and whose significata jointly partition the psychological color space" (Kay 1999). Informally, the 
assumption was that color is too salient a perceptual field to not be treated with lexical exhaustiveness. The Rossel figures do seriously undermine that assumption.

Mappings of the black and white, red, and green expressions are included in Figures 1-3. Numbers indicate the number of subjects who volunteered the relevant expressions on the WCS task. The table for the "red" terms needs a special note: the numbers here indicate the number of subjects who used at least one of the three red expressions. The terms taataa and mtyemtye were sometimes contrasted by speakers, but if not, they had very similar distributions, except that taataa had broader coverage. In contrast wuluwulu is restricted to darker reds ( $\mathrm{H}$ and I levels of brightness). Because of these competing terms, there is not much consensus in the red area: not a single chip in the red area had 70 percent (or 5) of the subjects agree on its name; 36 chips had 30 percent agreement on taataa, 20 chips on mtyemtye, and 5 on wuluwulu. If we conflate all the red terms, there is 70 percent agreement that 22 chips deserve some kind of red expression.

In the theory of basic color terms, category boundaries have played an ambiguous role. In Berlin and Kay, category boundaries are noted to be variable and unreliable, and consequently "they have been accorded a relatively minor place in the analysis" (1991:13). Nevertheless, when discussing the evolution of systems of terms from Stage 1 to 2, and so forth, Berlin and Kay (1991:17 ff.) hypothesized that boundaries would reflect the number of terms; thus, black would cover most dark hues at Stage 1 but would be successively eroded by the addition of red, green, and so forth. The Rossel system raises some puzzles for this perspective. If it is classified as a Stage 2 system, possessing "red," "black," and "white" basic color terms, then black and white should "continue to segment the middle range hues," while red should include "all reds, oranges, most yellows, browns, pinks and purples (including violet)" (Berlin and Kay 1991:17). But this is not the pattern: white and black are very restricted by subjects to almost hueless color chips, red does not extend in the expected way to yellows, and so forth. It appears that the currency of the other less conventionalized descriptive phrases, even if they are not restricted in number or literal reference, nevertheless serves to hedge in the extensions of the "white," "black," and "red" terms.

In later versions of the basic color term theory, category boundaries play a more important role: in addition to universal foci there are universal absolute boundaries, formed by the neighboring foci (Kay and McDaniel 1978:623; see also Kay and Kempton 1984, where boundaries were shown to have perceptual distance effects). Individual variability in category boundaries may be due, it is claimed, to ambiguities in the naming procedure. Composite categories are formed by (fuzzy) union of (fuzzy) focal categories. Thus, as mentioned, Stage 2 languages should have exhaustive coverage of the color space with just three terms: a "dark" expression focused in any of Black, Green, or Blue; a "red" expression focused in either Red or Yellow; and a "white" focused in White. If Rossel is seen as a Stage 2 language, then these are clearly the wrong predictions: the White, Black, and Red terms are primary not composite in character, and thus cannot 
Figure 1

"White" (top) and "Black" terms (bottom).

Numbers in unhatched cells indicate numbers of subjects extending the term to that cell.

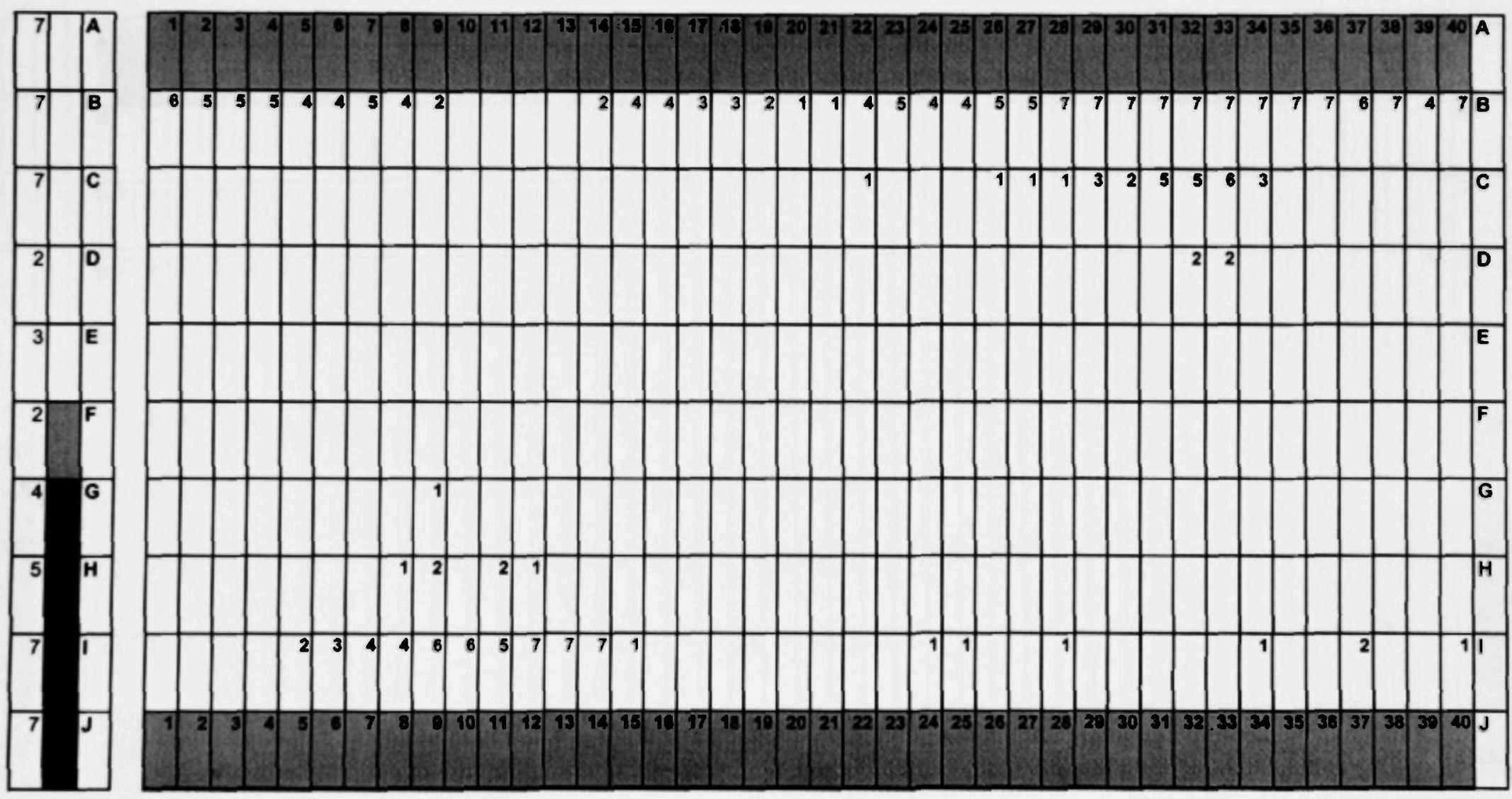


Figure 2

"Red" Expressions (all variants).

Numbers in unhatched cells indicate numbers of informants extending any of the three red terms to that cell.
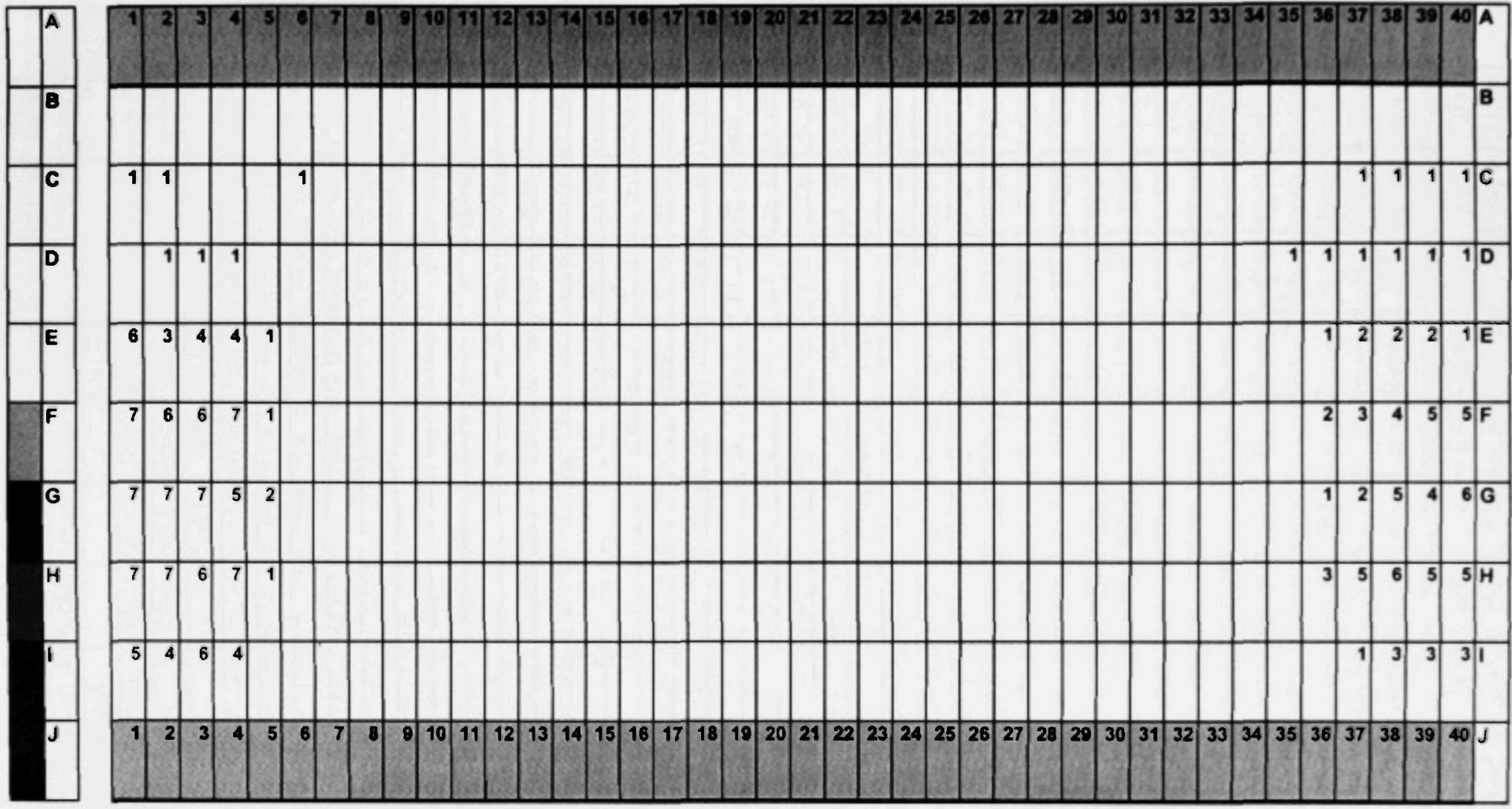
Figure 3

"Green" Descriptions (all variants).

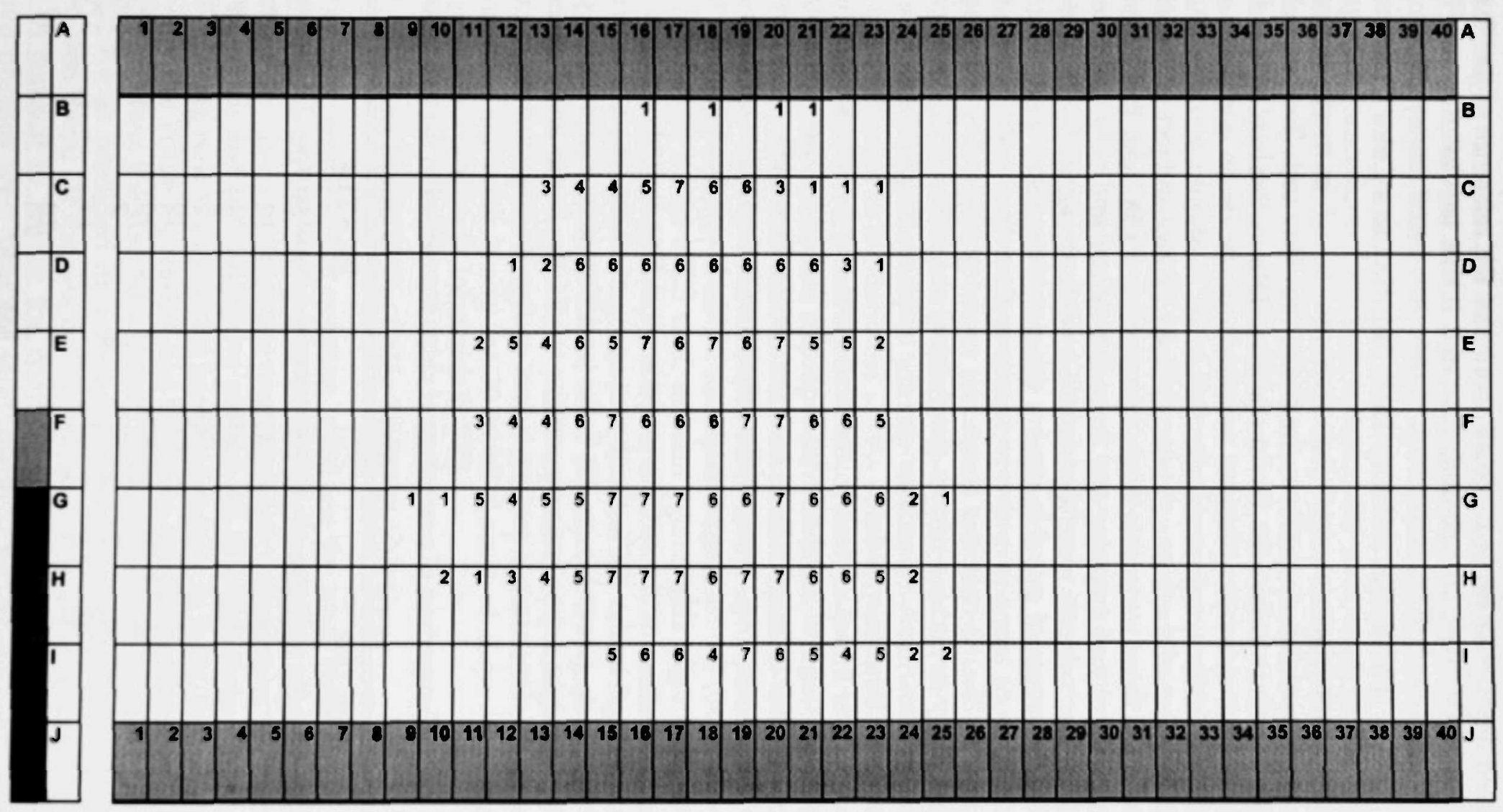


exhaust the color space. It seems that the availability of the less conventionalized descriptive phrases actually squeezes the reference of the "basic color terms" kpêdêkpêdê, kpaapikpaapî, mtyemtye, if that is what they are. ${ }^{37}$

\section{The Berlin and Kay Task: Pointing to a Color Chart}

For comparison, most subjects were also asked, in most cases on a subsequent occasion, to perform the Berlin and Kay task (for one subject, J, I was unable to collect the Berlin and Kay data as the light was fading, and an additional subject $\mathrm{Mu}$ was recruited). In the Berlin and Kay task, elicitation of color words and extraction of BCTs should be done in advance. Making use of the terms previously used by each subject in the WCS task, I selected those terms that might be considered a BCT for that subject, based on contiguity of mapping and frequency of use and willingness to locate a focus. The subjects were then asked to indicate again the focal exemplars and the range of possible use on the complete color chart. The range of extension of terms was always narrower than on the WCS task, for some subjects (like $R$ ) covering about half as many chips. The extensions were also likely to have a neater, geometrical shape (naturally enough, as the subject drew with a pencil around the chips on the chart subsumed within the color term in question).

As Table 8 makes clear, in the Berlin and Kay task no subjects were able to cover even half the chart with the terms that on the most generous criteria could possibly be considered candidate BCTs. Extensions were conservative in the extreme (e.g., two subjects refused to extend white off the pure white focus at all, the maximum extension of black was 13 chips, and the mean extension eight chips).

Comparison of the WCS and Berlin and Kay task shows that, whereas on average in the WCS about sixty percent of the chart is covered, only about thirty percent is on the Berlin and Kay task. The detailed pattern is as one might expect, namely, on the whole the Berlin and Kay extensions for each subject are a proper subset of the WCS extensions by the same

Table 8

Comparison of percentage of chips not named in the two tasks.

B\&K Task

Subject No of Terms \% Chips unnamed No of terms \% Chips unnamed

\begin{tabular}{cccrc}
\hline B & 6 & $82 \%$ & 12 & $57 \%$ \\
Mu/J* & 5 & $53 \%$ & 14 & $24 \%$ \\
E & 4 & $76 \%$ & 5 & $40 \%$ \\
M & 5 & $88 \%$ & 10 & $72 \%$ \\
R & 6 & $67 \%$ & 10 & $24 \%$ \\
Y & 6 & $51 \%$ & 7 & $29 \%$ \\
A & 10 & $64 \%$ & 11 & $37 \%$ \\
Mean & 6 & $69 \%$ & 10 & $40 \%$ \\
\hline
\end{tabular}

"Subject J performed the WCS task, and Mu the B\&CK task. 
subject. (There are a few anomalies: e.g., subject B only used one "blue" term, káami kîgha, once on the WCS but assigned a chunk of six different chips to that term on the Berlin and Kay procedure, suggesting that less psychologically salient terms may simply not be thought of during the WCS procedure.)

During both procedures foci were collected for each term, in the WCS task after the serial naming, in the BCT task before category boundaries, using the same stimulus. The whole collection of data points is mapped in the chart in Figure 5. For comparison, the relevant "universal foci" of Heider 1971 are marked in bold rectangular boxes. It will be clear that "universal" Black, White, Red, and Yellow are mostly near or on the centers of gravity of the corresponding Rossel color descriptions. Those who interpret the different Rossel red descriptors as contrasting, will also then have additional foci toward orange and brown (the foci for mtyemtye $[M]$ tend to be a little higher [lighter], while the foci for wuluwulu [W] are always darker). The yellow descriptors (marked Y), mostly referring to ripe bananas or desiccating leaves, cluster closely, except for subjects who opposed these similes, in which case the desiccating leaves descriptor had foci in dark-orange or brown (marked $\mathrm{Ch}$ ). Green descriptors (marked $\mathrm{K}^{\prime}$ ), based on the fresh/succulent metaphor, have a center of gravity well below "universal green" because of the allusion to the darkness of rain forest leaves, as noted above. Similarly, blue descriptors based on the káámi kîgha fruit (marked $\mathrm{K}^{\prime}$ ), have the dark-navy/purple reference appropriate, well below "universal blue." Those who used metaphors based on sea or sky had foci nearer to "universal blue," unless they opposed, for example, reef passage blue (marked C) to deep sea blue (marked N) when the foci spread apart.

The open nature of the WCS task, without prior restriction of terms or neglect of phrases, is undoubtedly a better exploratory procedure to test whether there are consistent categories behind serial responses. But the overall impression of the nature of Rossel color descriptors that emerges is not greatly different. Neither procedure yields a result that is consistent with the assumption that every language has a distinct lexical set that exhaustively partitions the color space, for 30 to 60 percent of chips are clearly judged indescribable by any locutions in Yélî.

\section{The Status of the Color Terms in Yélî Dnye}

We may now return to the question: what are the basic color terms in Yélin? We noted at the beginning that, from a linguistic point of view, there is no labeled domain, and there are two candidate form-classes, the reduplicated nominals and the descriptive phrases, all of which make reference to objects. Having now reviewed the naming behavior in tasks, we can add that: (1) only the White expression had no active competing alternates, the Black term had two, the Red term three; (2) these three reduplicated terms do not behave as predicted in a three-term system, carving up the color space between them; (3) the descriptive phrase yi kuu yâa was used by all subjects, in contrast to any of the competing Red terms; (4) many other descriptive phrases were used by individuals in a consistent, but often 
Figure 4

"Yellow" Descriptors (all variants).

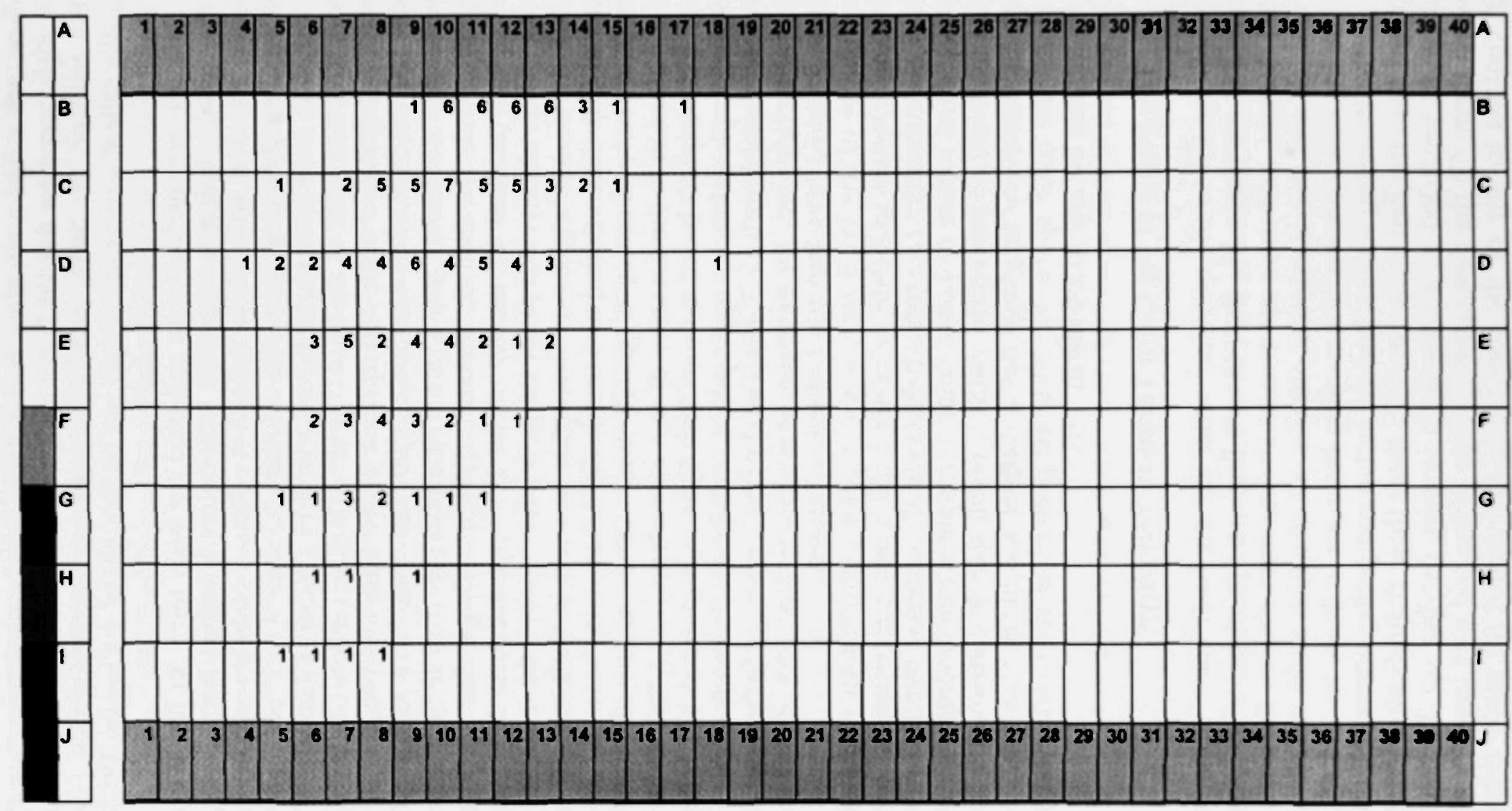


Figure 5

Foci for all descriptors in both WCS and B and K Tasks.

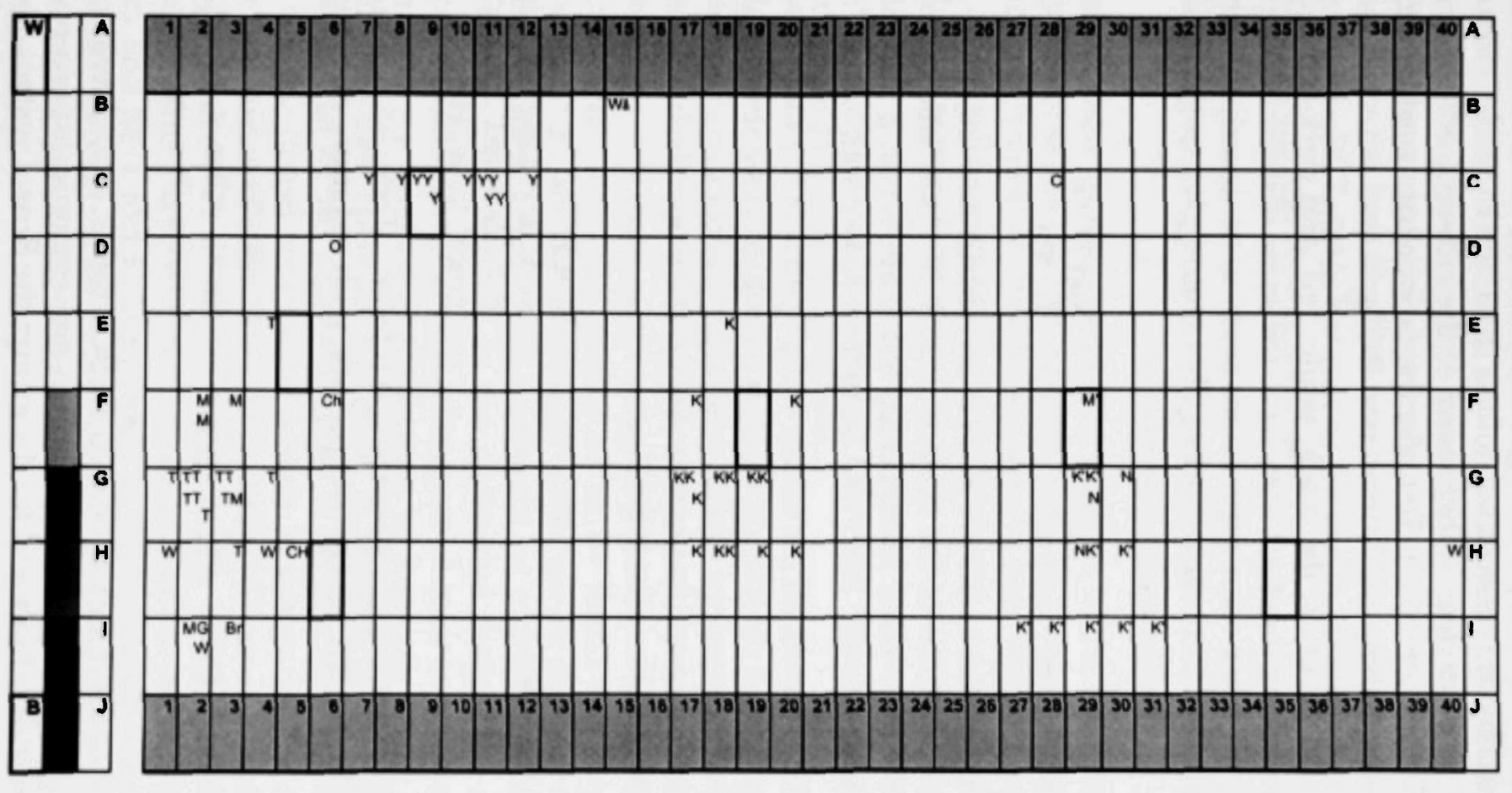

Bold cells = Heider's "universal foci"

$\mathrm{T}=$ tautaa 'red'

$\mathrm{M}=$ mtyemtye 'red'

$W=$ wuluwulu 'dark red'

MG = mbwe 'rotten'

$\mathrm{Br}=\mathrm{kme3}$ mbe 'brown mud'
$\mathrm{Y}=$ Yellow descriptors (e.g. yi chii yââ)

$\mathrm{Ch}=$ Yellow yi chii yâa when opposed to k:ii kîgha nt:u

$\mathrm{O}=n j: i$ wulu 'juice of tree[orange]'

Wâ = wâa vyîlê 'faded'

B = black terms
$\mathrm{C}=$ chênê 'reef passage'

$\mathrm{M}^{\prime}=$ mbóo 'sky'

$\mathrm{K}^{\prime}=$ kaami kigha 'blue fruit'

$\mathrm{N}=$ ntii 'deep sea'

$\mathrm{K}=$ all 'green' terms 
idiosyncratic, way; (5) all expressions revealed more variability in focus and extent than expected on comparative grounds; and (6) much of the domain remains unnamed by any means.

What should now be clear is that many of the criteria for "basic" status do not align (cf. Maffi 1990:327). To make the point clear, consider different grounds for distinguishing BCTs from non-BCTs:

1. On form-class grounds, the black, white, red, and dark-red reduplicated terms belong together: they have the same distributional potential. Nearly all other color expressions seem to be descriptive phrases with different syntactic distribution. This would give us the following division:

$$
\begin{array}{ll}
\text { vs. } & \begin{array}{l}
\text { Non-BCTs } \\
\text { the rest }
\end{array}
\end{array}
$$

The dark-red expression wuluwulu is then an embarrassment, for it is not a hyponym, and one-third of the subjects used it in systematic opposition. In addition, in the tasks other reduplicated terms appeared, if infrequently, like lókólókó 'bright, shining' from lókó 'luminous mushroom species'.

2. On semantic grounds, all the terms, except perhaps the main black expression, are based directly on reference to objects or natural states. In the major red expressions (taataa, mtyemtye), dialect variation seems to show this reference still has some salience. If we take the black case, seriously we would have the following:

$<15>$ BCTs

'black' (kpêdêkpêdê) vs.

Non-BCTs

'dark' (mgîdîmgîdî), 'white', 'red', 'dark-red', 'yellow', 'green', 'blue', etc.

3. On the basis of naming consistency and referential consistency in colornaming tasks, we get yet another picture, with red more dubious than green:

$$
\begin{aligned}
& \text { <16> BCTs } \\
& \text { 'black', 'white','green' } \\
& \text { vs. Non-BCTs } \\
& \text { 'reds', 'yellows', 'blues', } \\
& \text { 'orange', 'brown' }
\end{aligned}
$$

4. On the basis of the theory of composite BCT terms, as we have no composite categories and each color expression has a unique perceptual focus both for individuals and for the group, the Rossel system does not look like a three-term system at all. No composites implies at least a Stage 5 system with six terms, including blue:

$$
\begin{aligned}
& <17>\text { BCTs } \\
& \text { 'white','black','red','yellow', } \\
& \text { 'green','blue' }
\end{aligned}
$$

Non-BCTs

the rest ('orange', 'brown', 'grey', etc.) 
5. On frequency grounds, we would have a quite different assignment of "basicness." Davies and Corbett (1995:28-29) have suggested that frequency of use of names in a color-naming task may be used as a measure of the psychological saliency of expressions, and that this constitutes a mechanical procedure for deciding on BCTs. ${ }^{38}$ The terms that have the best linguistic claim to BCT status, then, will have relatively low BCT status because of the highly restricted extensions of the black, white, and red expressions:

$<18>$ BCTs
$\begin{array}{llll}\text { 'greens' } & \text { 'reds' } & \text { 'white' } & \text { 'black' vs. } \\ 65 & 28 & 25 & 13 \text { (mean no. chips named) }\end{array}$

I suspect there is little doubt that workers in the WCS tradition would classify Rossel as a Stage 2 language with BCTs "white," "black," and "red." But such a classification cannot be made on mechanical grounds. It would reflect an overall judgement about the linguistic and psychological status of the different expressions, with a variable weighting of different criteria.39 The extent to which Rossel does not behave as predicted by the Kay and McDaniel model (with no complete coverage and no composites) makes that judgment all the more uncertain.

\section{Concluding Remarks: Yélî Color Terms as an Emergent System?}

As mentioned in the introduction, a number of recent studies have raised the conjecture that there might be a different trajectory in the evolution of basic color terms than that posited either by Berlin and Kay (1991) or the later theory of the gradual elimination of composite categories. In both those theories, evolution begins with a coherent set of pure color terms dividing a preexisting color domain. In the alternative theory, the developmental trajectory would depict the slow emergence of color as a systematic semantic domain and the gradual crystallization of hue-only terms under specific cultural pressures. There are a number of features of the Rossel terms and their usage that fit this alternative view of an emergent system. First, all, or nearly all, the Rossel terms have a basis in names for, or descriptions of, objects that exemplify the color in question. There is nothing rare in this (see, e.g., Senft 1987, or Martu-Wanga in the WCS), but object names as color descriptors may be context restricted, fail to exhaustively cover the domain, and have foci in hues closer to the exemplars than to perceptual landmarks. ${ }^{40}$ Second, in line with their low functional load and relative lack of conventionalization, the Rossel terms show large variability in many different aspects:

1. Forms. Apart from the white term, all expressions had variant forms; many forms are inventive descriptive phrases, some subjects volunteering, for example, blue expressions, while others did not.

2. Foci. Although all subjects agreed to focus the black and white terms in pure black and white, beyond that there was little consensus. 
3. Range. Although all subjects agreed to restrict black and white expressions to colors fairly near pure white and pure black, beyond those expressions there was little consensus on denotational range, with variations of the order of eight times the area covered from one subject to the next.

Third, speakers were able to produce a rich set of terms that denote hues through descriptive content, including nonce terms of their own invention, and these terms, despite their relative lack of conventionalization, had systematic impact on the focus and coverage of the more conventionalized part of the system (i.e., the reduplicated terms). And fourth, averaging over speakers and tasks, most of the color space remains unnamed by any expressions, however inventive. This suggests that the color space is not perceived as a natural semantic domain to be exhaustively named in its entirety.

Another important point is that the location of the Rossel system in the BCT evolutionary stages is fundamentally unclear. On purely linguistic grounds, it might be thought to have at most three BCTs, with only two (black- and white-designating expressions) uniformly established, and thus to be a Stage 1-on-the-way-to-Stage 2 language. But looking at response patterns, the descriptive simile that serves as a green expression looks better established than the red terms, suggesting at least a Stage 2-on-the-way-toStage 3 classification. However, none of these "early"-stage classifications is consistent with the fact that there are no signs at all of any composite categories, that is, categories with more than one focus (a Stage 2 classification predicting that the "black" term should be a composite category covering blue and green as well, with the "red" term covering both red and yellow).

One possible explanation for variability and typological unclarity is that the language is undergoing fundamental linguistic change. This kind of explanation has been given for other such cases by, for example, Kay (1975), who demonstrates age stratification and other systematic sociolinguistic evidence of change in progress. ${ }^{11}$ Moreover, Kay claims, the variation patterns according to the universal constraints (so that, e.g., incipient BCTs at one stage are clearly fractionated out in the subsequent stage). For the Rossel data we cannot, given the small sample of subjects (skewed to higher educated males) and the lack of earlier studies, definitively rule this kind of historical-sociolinguistic explanation out. There is, despite the remoteness of the island, significant exposure to English through primary education (in this area widespread since the 1950s) and migrant work and selective secondary education on the mainland. But in my small sample there is no obvious age or education stratification of responses. Although the sample is not balanced for sex, it does, however, cover the spectrum of Rossel-English bilingualism (from more or less monolingual Rossel to more or less bilingual speakers). Yet no English loans, or loans from the surrounding Austronesian languages, were employed (this contrasts with another Milne Bay language, the Trobriand case investigated by Senft [1987], where English terms were frequently used). Finally, the patterns of innovation (displayed in the less established expressions for which there is no consensus) are really not at all English-like: Rossel innovations include dark-red expressions; light 
versus dark blues; and up to four distinct "yellow" expressions, each with foci displaced significantly from the "universal foci" and, however elaborated the set of terms, not associated with any notion of the exhaustive partition of the color space. Overall, then, I do not think we can dismiss the case as change in progress.

An alternative line of explanation is that, on Rossel Island, color is simply of minor communicational import, handled by a range of descriptive phrases, only a few of which have any standardization approaching BCT status. As mentioned, the traditional culture employs very little in the way of dyes or paints, instead using feathers, flowers, or leaves for ornamental color-it is only when color is detachable from objects with inherent colors that a color terminology has any real communicational function. For lack of a superordinate, people would even find it hard to express the otherwise appropriate Bellona view that "we don't talk much about color here" (Kuschel and Monberg 1974). ${ }^{42}$ Lack of functional load would help to explain the variability, the relative lack of standardized expressions, their failure to cover the domain, and the many supplementary, often ad hoc descriptive phrases. In retrospect, a number of other reports seem to suggest an at least partially similar lack of functional load, with high speaker variability both in terms and their extensions, and only partial coverage of the color space - the details in, for example, Berlin and Berlin 1975; Dougherty 1977, 1978; Heider 1972; Jones and Meehan 1975 look more like the Rossel findings than the treatment in subsequent publications would suggest. Consider, for example, the findings of Davies and associates:

It became evident that the Batswana concept of color is rather different from, and less salient than, that of many other languages.... The difference is indicated by the ... large number of terms used to describe the "surface patterns" of cattle.... The lower salience of the concept is indicated by the hesitancy in offering color terms ... a and by the small number of tiles named. . . . Five-year-old Batswana appear not to understand the color concept, ... whereas an American fouryear-old . . . can correctly use the 11 basic color terms. [1992:1095]

Let me adduce parallels on just one point of convergence with these earlier studies - the way in which ad hoc metaphorical or descriptive phrases may hedge in the meanings of better established terms, thus eliminating composite categories that might otherwise be expected. Dougherty (1977) shows for Futunese that the range of the "black" and "white" expressions for each speaker varies according to how many other terms that speaker uses (although in all cases she finds a much broader extension than the Yéli terms). It is also clear that metaphorical terms, for example, rounemahmata 'living/green leaf', if used, then restrict the application of BCTs like uiui, a grue term, which is consequently used to mean only 'blue' (1977:112). This is important because it means that from a semantic point of view the BCTs cannot be isolated out from the non-BCT expressions-they together divide up the color space. Dougherty goes on to document a great deal of speaker variability, with speakers ranging from Stage 3 right up to Stage 7 on the Berlin and Kay scale (although here change in progress is substantiated). 
Similar observations can be made of the otherwise very different Dani system, usually categorized as a Stage 1 language with only "black" (mili, darkcool) versus "white" (mola, light-warm) categories, which is in fact described by Heider (1972) as in transition toward a hue-differentiated system. She notes that half the subjects have a red term, which may be either pimut or boksu, denoting a red clay, somewhat fewer had a term for yellow (bodli, 'turmeric'), and one-quarter had a term for blue (juaiegen, bud of a flower species'). Other descriptive phrases, not reported, were also in use $(1972: 456)$. All these terms, beyond the black and white terms with general use, are object names but, Heider argues, should not therefore be dismissed as not real color terms (1972:463-464). She also provides evidence that these less well established names have an impact on the shape of the better established system. Thus, nearly all speakers who have a light, pinkish focus for mola 'white/warm' also have a red term: their less than fully conventional red term is effectively squeezing the extension of the fully conventionalized 'warm' term out of the red area. Again, as in Rossel, the non-BCTs seem to form a system with the BCTs. (In other respects the Dani case, with its systematic composite terms, is quite at odds with the Rossel system.)

The empirical findings of Berlin and Kay or the WCS can be laid out simply as an implicational scale, restricting patterns of co-occurrence, as is the general practice in linguistic typology. It is the diachronic or "evolutionary" perspective, suggesting an inevitable progression through the patterns, that brings the anthropology back in (and keeps the critics hopping; see Saunders and van Brakel 1997), promising links to technology, aesthetics, or local practices, and predicting specific patterns of variability under social change. The evolutionary progression seems to have been understood in two ways: on the one hand, as the simple accumulation of BCTs, gradually filling the color space (an interpretation derivable from Berlin and Kay 1991, encouraged by the figures with unnamed spaces); or, on the other hand, as a progressive subdivision of a color space that is always exhaustively named (the view increasingly made explicit in work from Kay and MacDaniel 1978 on).

But philologists have long maintained a different kind of "evolutionary" view, one in which languages have slowly evolved hue-denoting expressions from object names, context-restricted terms, and terms for brightness contrasts. Thus, even the superordinate terms for "color" in Indo-European languages come from such context-restricted words for hair or fur color patterns (Buck 1947:1050), while brightness descriptors and object names clearly are a major source of color expressions in the history of Latin and Greek (Lyons 1999) or indeed English (Casson 1997). Brightness descriptors clearly play such an important role that MacLaury (1992) has even developed a parallel evolutionary scheme for such terms, imagining that the brightness and hue streams flow into one another at various points of development. This view emphasizes the ways in which pure hue terms struggle to emerge, as it were, under specific cultural and technological pressures (e.g., Casson [1997:236] links the culmination of the English brightness-tohue transition to the impact of the Italian dye industry in the 15th century)." 
Kay, in commenting on Lyons (1999), has attempted to crystallize this philological view as "the Emergence Hypothesis" or EH. Kay says,

Berlin and Kay tacitly assumed that there is a small set of pure color words (or word senses) in every language that partitions the color space.... Lyons' main point is to challenge this assumption ... and to suggest that some (many?) languages contain no set of pure (i.e., unrestricted) color terms whose denotata jointly exhaust all the color sensations. [Kay 1999:76]

Kay isolates Lyons's main arguments for the EH as follows: Some languages have expressions used in the color domain that exhibit (1) synonymy, (2) cover noncolor properties too, and (3) are more about light-dark oppositions than about hue. Kay responds that (1) synonymy can be expected in systems under change, (2) the apparent generality of terms over hue and non-hue properties may just be polysemy or ambiguity, and (3) the prominence of light-dark oppositions in early systems is in fact predicted by Kay and McDaniel. Kay was therefore of the opinion that, although it should be investigated further, on current evidence the EH has no empirical foundation (although, partly in response to the current article, Kay and Maffi [1999] take a different line).

But the EH cannot be disposed of quite so easily. The EH challenges the idea that the color domain is a natural, universal semantic field at the outset-that is, it suggests that in some societies color terms carry such a low functional load that there is no fully systematized lexicon of color. Symptoms that might indicate lack of an established semantic field may include the following (cf. Davies et al. 1992:1095):

1. No clear way to elicit color responses as opposed to other perceptual properties of objects (no differentiation of question frames).

2. No clearly articulated sense relations among the expressions: specifically no superordinates (no word for "color"), no hyponyms (no clear sense that, e.g., the expression for "dark-red" is a kind of "red"), no antonymic pairs of expressions.

3. Many expressions deriving from terms referring to objects or states with canonical hues, such that a tension may result between the actual hue so exemplified and the perceptually focal hue in the color space.

4. Color-indicating expressions failing clearly to meet the conditions for BCT status, and the different criteria (morphosyntactic, semantic, psychological) failing to align.

5. Such expressions failing to exhaustively partition the color space, even when ad hoc descriptors are counted in.

6. Large intraindividual and interindividual variation in color naming, especially where such variation is not accounted for by sociolinguistic stratification.

7. Low frequency of color-referring expressions in texts, and hesitancy and latency in production.

When these extra symptoms of lack of a conventionalized semantic field are taken into account, I think that there is a large amount of circumstantial evi- 
dence in favor of the $\mathrm{EH}$, not only in the philological traditions and in the Rossel data, but also in many other detailed field studies (q.v. Berlin and Berlin 1975; Dougherty 1977; Heider 1972; Kuschel and Monberg 1974; and many WCS researchers, who all mention elicitation difficulties, hesitations, large variations, and problems with BCT definition). In short, if the evolution of BCTs is understood as slow isolation, consolidation, and systematization of hue expressions, "early" systems may be more diverse intraindividually, interindividually, and cross-culturally than the BCT tradition predicts.

Let us suppose, for the sake of argument, that the $\mathrm{EH}$ is correct: what would the consequences be for BCT theory? Kay holds that "an empirically established EH might more likely serve to extend the Berlin and Kay model than refute it" (1999:88).44 But in fact the coarticulation of the EH and the Berlin and Kay theories is not straightforward. Consider the alternatives. One would be that there are two phases, an EH phase whose output was the input to the Berlin and Kay stages-the idea would be that one first had to evolve the very idea of the "basic color term" as it were-and then the Berlin and Kay stages would apply to all further developments. But the evidence in favor of the EH phase comes from languages that are already roughly assignable to a series parallel to the Berlin and Kay Stages 1, 2, or 3 (not exactly, of course, because such languages may only exhibit protoBCTs). The alternative model would be a kind of parallel evolution of Berlin and Kay languages and $\mathrm{EH}$ languages, with various cultural, linguistic, and psychoperceptual pressures accumulating for $\mathrm{EH}$ languages to converge on Berlin and Kay language patterns. So one might think about the Rossel case as on the EH scale, showing the same tendency for lexicalization in the order black/white > red > green > yellow > blue, and so forth as can be found in the Berlin and Kay scale (and so responding to the same psychoperceptual pressures), but where the relatively low functional load has failed to congeal a clear set of BCTs, with the consequence that the black, white, and red terms simply do not have the composite structure expected on BCT theory, because they belong to a larger, looser set of non-BCTs that nevertheless fails to exhaustively cover the color space.

Now such a dual evolutionary track at first sight appears theoretically very weak: almost any exception to a Berlin and Kay language could, it seems, be accommodated in the EH category, with the consequence that Berlin and Kay "universals" may become much weaker and hander to falsify. However, Kay and Maffi (1999) have now developed an ingenious model that provides two developmental routes, an EH versus a Composite Category route, with a point of convergence. Not to spoil the story, I give just the outline: a language like Rossel is an $\mathrm{EH}$ language where a semantic field of color has not yet jelled and there is no exhaustive partition of the domain, but there are good noncomposite candidates for Black, White, and Red. The next stage will be just such an exhaustive partition as occurs at the beginning of the Composite Categories route, and it may force the recognition of a single term that covers the rest of the domain and thus includes Yellow, Green, and Blue under a single description. Such terms, combining Hering opponents Yellow and Blue, are attested and have till now been an 
embarrassment for $\mathrm{BCT}$ theory. The $\mathrm{EH}$ route toward a coherent color lexicon predicts their occurrence. Kay and Maffi (1999) have developed a set of optimality principles that predict that $\mathrm{EH}$ languages will jell into Berlin and Kay languages not later than this point, that is, from systems with Black, White, Red terms and ad hoc descriptors for the rest of the hues, into systems with Black, White, Red terms and a Yellow/Green/Blue composite, which will then successively split in orderly ways (into, e.g., Yellow versus "grue," as in Tzeltal, or "yeen" versus Blue, as in Cree).

Whatever the success of this new theory (and there may be doubts that it deals with the kind of "late" stage inchoateness reported in, e.g., Davies et al. 1992; Dougherty 1977; Lyons 1999), one thing has fundamentally changed. The existence of languages with such emergent color terms has undermined the original presupposition of BCT theory, namely, that the hue spectrum is universally a natural semantic field systematically covered by a lexical set. This has the consequence that we must give up one of the very few "absolute" linguistic universals in the semantic domain, that is, the claim that all languages have a set of BCTs exhaustively describing the color domain. The theory of basic color terms has been taken, especially outside the field, to have fatal consequences for the doctrine of linguistic relativity:

The cross-cultural results such as those reported in Berlin and Kay (1969) ... provide little support for the Whorfian hypothesis that language structures how we perceive the world. Instead these results appear to be more consonant with the idea that the innate biology of our perceptual system structures the way we use language. [Shepard 1992:522]

Yet, as the progenitors of the theory themselves remark, "sweeping conclusions of any kind in the area of culture and biology appear unwarranted by currently available facts"; the most that has been claimed is that "the semantics of basic color words in the straightforward expression of visual experience is partially constrained by parameters of the visual system" (Kay et al. 1991:24). There is nothing in the Rossel data or other recent literature to undermine that conclusion (pace Saunders and Van Brakel 1997). But the emergence hypothesis recognizes that those universal perceptual constraints do not directly engender semantic universals of color terminology-it takes a culture of color to make a color terminology worthwhile.

\section{Notes}

Acknowledgments. This article was submitted just after presentation in a seminar at the Max Planck Institute for Psycholinguistics, June 1997, with a response by Paul Kay. It was Paul who suggested the study and, in the best scholarly tradition, embraced its unexpected findings. Partly in response to this paper, Kay and Maffi (1999) have suggested fundamental changes to the theory of basic color terms (also delivered in a seminar at the MPI, October 1998). In revising this article, I have tried to keep close to the original that evoked the Kay and Maffi response, hoping to avoid indefinite reflexivity, but I have been forced to remove my speculations about what I then imagined they would have to say in response, and so have incorporated some 
response to their new ideas in the introduction and conclusions. I am grateful for a number of comments from my colleagues Penelope Brown and David Wilkins; Jim Henderson, pioneer of Yélî Dnye studies, provided detailed comments and corrections on a draft, for which I am most grateful. Finally, my thanks go to the anonymous reviewers and to the editor for forcing me to clarify my views.

1. MacLaury 1997 and Saunders 1992 contain some reflections on the reception of the book from different perspectives.

2. The Munsell system is based on the standard view that the psychophysics of color perception involves discriminations on just three parameters: "in operational terms a normal subject can match the color appearance of any given surface by adjusting three - but no fewer than three-knobs on a suitable color-mixing apparatus" (Shepard 1992:496). Note that the standard dimensions of hue, saturation, and brightness are polar coordinates, but that the color sphere can as well be described in three rectangular coordinates, green/red, blue/yellow, light/dark, to match the Hering opponent system adopted by Kay and McDaniel (1978). For why we might have evolved such a tridimensional system, see the suggestions in Shepard 1992 that it arises from the need to achieve perceptual color constancy of objects under three dimensions of variation of terrestrial illumination. For an attack on the tridimensional assumption, see Saunders and van Brakel 1997.

3. Color terms with initial capitals indicate metalinguistic terms, based on foci within the Munsell set.

4. The variation was also attributed to different stages in ontogenetic development, with ontogeny paralleling cultural phylogeny (i.e., the evolutionary order of acquisition of BCTs). See, for example, Boster 1986, Dougherty 1977, and Harkness 1973. But in fact individual children are highly idiosyncratic, and in English anyway they tend to learn, for example, blue and green before white, black, or red (Bartlett 1978).

5. Maffi (1990), for example, shows that of the six BCT-like terms in Somali, which have both nominal and verbal forms, three are basically nouns allowing the derivation of verbs and three are verbs allowing the derivation of nouns (as in the subset of English BCTs with causative derivations in -en); these are the red, black, and white terms, suggesting an earlier Stage 2 foundation for the Somali system. Dixon (1982:35 ff.) gives some interesting information on the form-class associates of color terms in about twenty languages. Lucy (1997a) has challenged whether color terms ever constitute a form class; Dixon shows that, for example, color plus dimension terms, or speed, color, and other physical properties (like rough/smooth, heavy/light), may often constitute a delimited major form class. The best evidence for a color-only overt form-class is from Chemehevi, where the color subset of adjectives must be suffixed with a special stative or inchoative marker (Wetzer 1995:9).

6. An additional long-running complaint has been that the stimulus array is simply biased to make the "universal foci" unnaturally salient (Lucy and Shweder 1979; but see, e.g., Collier [1976], who shows that when the existing saturation biases are removed no different results are obtained). The chart is also systematically distorted, from the point of view of psychophysical distance between colors, by the "Mercator" projection of the color sphere onto a two-dimensional chart, with maximal differences in hue between chips at the equator. It is perhaps worth pointing out that in fact in the early works that followed Berlin and Kay there was a fair degree of variant stimulus material and methodology (see, e.g., Heider and Olivier [1972], who use only half the Munsell set in Berlin and Kay 1991 and use it in different ways; Berlin and Berlin [1975], who use objects matched to Munsell colors; and so forth). 
7. Apart from the celebrated Hanunóo case, the numerous cattle-color systems of East Africa are good examples of color-plus-pattern (e.g., darker mane plus lighter brown coat, or vice versa). See also Lyons 1995.

8. A proper analysis of both the intra-and interlinguistic patterns here may in fact be most revealing. Dixon (1982:23), for example, points out that in English only three color words permit inchoative/causative forms in -en (blacken, whiten, redden) and that these follow the Berlin and Kay hierarchy (see also Maffi 1990). Dixon claims that color is one of the seven underlying semantic fields that universally are associated with an adjective class in those languages that have adjectives. A more recent study has cast doubt on this, suggesting that color is more peripheral to adjective classes than Dixon thought, perhaps because so many color words are derived from prototypical object names (Wetzer 1995:9 ff.). A major ideological divide between BCT theory and its critics is the question of whether one should expect to find a covert or overt form-class corresponding to an underlying semantic domain: Rosch (1977) pooh-poohs the expectation, Lucy (1997a, 1997b) assumes it. David Wilkins (personal correspondence) points out to me that the very theory of the evolution of BCTs suggests an accumulative model with, say, red, white, and black as one minor (or covert) category, green and blue and so forth, belonging to a slightly different microcategory. This is in fact precisely what has been found by, for example, Maffi (1990) and Dixon (1982).

9. See Kay and Kempton 1984:67 for a response; see also Collier 1976.

10. Davies and associates (1992:1066) claim that only six field studies with monolinguals had been conducted by 1976, to which they add Senft 1987 and their own work, and should add MacLaury (1991) and others (not counting the more limited but extensive data gathering of the World Color Survey, conducted 1978-79). Still, full-scale field studies with surrounding linguistic and ethnographic work perhaps do not exceed a dozen.

11. And, as it happens, in the aftermath of a severe cyclone, which effectively limited the number of subjects. In all, 11 speakers were consulted, but only eight completed detailed tasks. I have made five field trips to Rossel Island, investigating spatial language, kinship terminology, grammar, and discourse.

12. The oldest reliable information comes from the ethnography by Armstrong (1928). He notes that at that time baskets had patterns woven in by means of "threads being darkened by being buried in the ground" (1928:11); this technique still survives, pandanus being submerged in mango mud to yield a blue/black color. Occasional imports of dye by the prior missionary led to baskets being made with red against natural pandanus. The only major art form was the canoe prow board, "picked out in red, blue and black" (Armstrong 1928:11). The oldest specimens I have seen (perhaps 25 years old) are picked out in red, white, and black, as is common amongst the Massim-and indeed they may have been imported. Nowadays carvings on canoe hulls are left uncolored.

13. The hypothesis indirectly alluded to here is that literacy (with the preparation of papers and inks) correlates with developed color technologies, and that, in line with the emergence hypothesis to be discussed below, the possession of a superordinate for the color domain is a recognition of cultural salience of the color field. On sense relations within the color domain see Lyons 1999.

14. In answer to the question, "Vyêm ló ntê 'nmeni?" [White-pigeon, what-like bird? i.e., What is the white pigeon like?], I have had the response, "Ala nté a mbum yêde" [It cries like this (demonstration)]-indicating that all perceivable properties, not just visual ones, are within the scope of lonté.

15. I think that the matter of the question eliciting a color description is more important than it at first seems. Lyons (1995), for example, assumes that the color terms 
elicited by Berlin and Kay tasks are "second-order" terms and thus nouns; Kay (1999) argues that they are first-order terms and thus predicates. The distinction is clear in the ambiguity of "That's brown," read as "That is the color brown" versus "That object is brown in color." But the two readings correspond to two different questions: "Tell me the name of this color" versus "What color does this chip have?" One doubts that the question frame in surveys like the WCS has in fact been properly controlled (see for example Saunders 1992:185 ff.). In cases where there is no superordinate term color, such fine discriminations are perhaps irrelevant anyway. In some languages, for example, Arrernte, which has no superordinate, one forms a question about color along the lines, "What is it like? Is it black?" (David Wilkins, personal correspondence); but such a strategy is not idiomatic in Rossel.

16. Rivers reporting on the Torres Strait expedition at the beginning of this century mentions a number of similar cases, where, for example, the red term is clearly derived from object reference, but one or the other or both of the black and white terms are not (see extended quotes cited by Berlin and Kay [1991:38-39], who assign these systems to a probable Stage 1 status). Intriguingly, in the Rossel respect vocabulary used only on sacred Lów:a islet, there are only two color words: nyipinyipi 'white', reduplicated from a nominal of obscure reference, and mgâmumgâmu 'black', transparently from $m g a ̂ m u$ 'flying fox', the dark bat found in large quantities on the islet.

17. There are various antonyms, meaning "bright, shining," like wuu in "D:ââ wuu ndñ" [The moon is bright] and dnyendye in "U pâa dnyednye" [It is bright], but they were not used in color-naming tasks.

18. It is possible that the classifier nominal is in fact the head noun, thus aligning with the normal order of the head in compound nominals. If so, the example that follows would gloss more like "this bookish bundle is red" than "this bundled book is red."

19. However, this preference for a specification of a surface property also holds for other adjectives (e.g., ngomo pââ ntîn, "house body big"). In the negative, moreover, the specification of the surface property is more freely omitted:

\section{Ala puku dmi (u pââ) daa mtyemtye \\ This book bundle (its body) not red \\ "This book is not red"}

20. Jim Henderson (personal correspondence) suspects this to be an English-influenced structure.

21. I owe this observation to David Wilkins.

22. Wittgenstein (1958:7, $25 \mathrm{ff}$.) likens the naming of colors to measures of length: both work by reference to external prototype samples, or standards. This contrasts of course to BCT theory, where Red has an inner immaterial standard, given by our perceptual system. "But," warns Wittgenstein, "don't clutch at the idea of always being able to bring red before our mind's eye even when there is nothing red anymore" (1958:28). What will emerge below is that the external objective prototype and the internal focal prototype can be in real tension. See also Goodwin 1996.

23. This is a phonological variant, or neutralization, accorded dialect status by informants (chii is Njinjopu dialect, tii Damenu dialect), but is in fact in free variation in, for example, Njinjopu, the locus of this investigation.

24. One intriguing issue is what exactly underlies the choice of such standardized exemplars as káami kigha. One might suppose that a culturally important foodstuff would be an ideal candidate; but why then, for example, is the much prized, and strikingly bright, scarlet fruit of the pandanus (mty:uu vyi, exemplifying roughly 
Munsell F2)_or other such possible reference objects_never a source of such similes? On multiple 'blue' terms, see Davies and Corbett 1994.

25. Despite the great amount of work on color terms, there is no adequate theory of what is in fact a semantically unusual field. For example, English BCTs are in some sense contrastive, but unlike many cohyponyms they are not incompatibles: as Frege pointed out a century ago, there is no logical incompatibility between "red" and "green," and Griceans have been concerned with the implicature from " $X$ is white" to "X is solely white" but without the benefit of an underlying semantical analysis (see Frege 1953:22; see also Harnish 1991:316). Further, while black and white are felt to be antonyms, no other antonymical relations clearly hold linguistically (corresponding, e.g., to the Hering opponents). (The special antonymic relation of "black" and "white" terms thus confounds sorting tasks of the kind explored in Davies and Corbett 1998.) Newton's color circle is, feels Cruse (1986:190), reflected in a uniquely cyclical semantical structure. Hyponymical relations are also none too clear: to take the best case, if crimson is a "deep red inclining towards purple" (Oxford English Dictionary), is it really a kind of red (and not, e.g., the intersection between primary red and derived purple)? Turquoise is said to be a kind of blue (Oxford English Dictionary), but the prototype stone varies from apple green to sky blue. In short, we know far too little about the internal structure of the semantic field even in English.

26. More recent definitions in the same tradition: "the smallest subset of color terms such that any color can be named by one of them" (Kay et al., reported in Hardin and Maffi 1997:349 in a discussion of other recent proposals). Hardin and Maffi (1997:349) suggest that a basic color term is simply one that is general (in application, and not a hyponym) and salient (readily and consistently elicitable). Paul Kay tells me that the criteria spelled out in Berlin and Kay 1991 were intended to operationalize existing practice and were never intended as rigid criteria as opposed to rules of thumb.

27. See, for example, Moss (1989), who complains that the criteria conflate linguistic, psychological, and physiological levels that are best kept analytically apart precisely because they do not align.

28. Crawford (1982) objects to the conditional structure of Berlin and Kay's criteria: if not clearly a BCT by criteria $i-i v$, then and only then check if it satisfies criteria v-viii. But as Kay admits, these are all only rules of thumb.

29. See, for example, Senft (1987) on Kilivila. Kay et al. (1997:48) describe MartuWangka as a Stage 4 language even though its white, black, red, and green terms are derived by reduplication, mostly from nouns, for example, mijimiji, 'red', from miji, 'blood'.

30. On the other hand, when considering a Highland Papuan language, they remark, "Bromley indicates a third term, getega for 'green'. However, the term is analyzable into get 'fresh', and ega 'leaf'. Elsewhere Bromley ... . indicates that the expression is best treated as a descriptive phrase and not as a basic color term" (Berlin and Kay 1991:51).

31. The stimulus charts were vintage originals from the Berkeley Language Research Laboratory, with small (circular, 6.5-millimeter diameter) punched color samples, arranged in an array 33 by 8 centimeters. There are in fact 410 samples on the card, for it is bounded by 40 identical white chips at the top and 40 black chips at the bottom, representing the poles of the color solid. To the left of the hue array, which represents the projection of the saturated surface of the color solid, were ten chips from white to grey, representing the unsaturated polar axis. The 330-chip array is illustrated in color in the first issue of this joumal (Kay et al. 1991). The Berlin and Kay procedure actually requires two such charts, each breaking the Newton 
color circle in a separate location (in the greens or in the reds), so that the subject can always ring an unbroken color category.

32. In fact, the chips are shown in a single fixed, randomized order to all subjects. This is less than ideal, but already difficult enough in the field. There are possibly ordering effects, as one might, for example, dissent to a chip being "black" on the grounds that the prior one was "blacker"-so true randomization over subjects would be desirable.

33. The Munsell color chart is perhaps not the ideal reference, as it is not based on exact psychophysical minimal discrimination distances (in part because of the distortions of two-dimensional projection from the color solid). For this reason the array has been claimed to yield artifactual "peaks," glorified as universal foci (Lucy and Shweder 1979; but see Collier 1976; Jameson and D'Andrade 1997). However, the fact that nearly all other linguistic investigators utilize the Munsell set is an overwhelming case for continuing to use it, especially as conversion of the data to CIE coordinates and other systems is said to be not always possible (Davies et al. 1992:1097). The wavelength equivalents of the Berlin and Kay BCT foci are, however, conveniently given by Lumsden 1985 .

34. The Ishihara tests do not control for blue/yellow deficiencies, which just may be a significant factor in the tropics (see Davies et al. [1992:1069], who recommend the City University Color Vision Test). There has to be a suspicion that physiological differences in human populations have been seriously underestimated in this domain (see Bornstein 1973 on tropical adaptations; Furbee et al. 1997 on eye color; Sacks 1996 on color blindness in island populations; and so forth).

35. I experienced the normal unforeseen difficulties accompanying any task in the field. For example, one subject would give me both "black" and "white" expressions for the same (dark) chips. I attributed this to the fact that the acetate sheet in which the chips are encased is reflective, so that held at the right angle they would indeed become light, opaque, and reflective. These difficulties are not uninteresting: we start from a presupposition of a clear notion of the inherent color of objects, while I was asking literally, "How does it seem/what is it like?" there being no way to ask, "What is its inherent color?" Thus, my subject's close phenomenological observation was, he thought, exactly what was called for. (Chips incidentally were held up by me and offered to the subject to examine in his or her own hand if so desired.) However, using the same stimuli, MacLaury (1991:39 ff.) found a small minority of Mesoamerican informants who gave a "white" response for black chips, which he took to be a widespread, but marked, naming of black as "white." Discovery or artifact?

36. There are just a few clues that this conservative extension of the black expression may be an artifact of the method of elicitation. One elderly speaker of the western dialect was heard to describe dark-red bagi (shell necklace) with the black term ("U ntââ a pwile ghi kpêdêkpêdê ngmanyi l:âmo, n:aa pywupwi" [Please make dark/black bagi, I'll buy it]). The traditional dye for basket making is mangrove mud, which yields a variable result ranging from navy blue to black, but this shade is invariably called kpeddekpêdê. In natural usage it may be that the "black" expression can be used to mean "dark," just as the "dark/night" expression (mgidimidi) can definitely be used to mean "black."

37. As an example, consider the case of informant $A$ who used the phrase yi tii yad (tree desiccating leaves) as an orange/brown descriptor (he had another phrase for yellow, k:ii kigha ntuu, ripe banana fruit); this orange expression squeezed yellow and red into the primary color areas.

38. Testing English subjects on a chip-naming task, Davies and Corbett found that "each basic term, except white, scores higher than every non-basic term" 
(1995:29) with mauve and turquoise outranking white. If one looks at consistent naming of specific tiles, then white outranks mauve and other non-BCTs. It is notable that their subjects also used blue and green with far higher frequency than red, white, and black. On a task where subjects are just asked to list all the color words they can think of, BCTs are correctly predicted to be just about equally frequent.

39. For example, the fact that consultants think that the Black and White terms are antonyms suggests that these have a special status; no one could think of an antonym for the Red terms.

40. The difference between real color words and object names as descriptors can be nicely seen (David Wilkins points out to me) in the Anbarra system of Arnhem Land (Jones and Meehan 1975), which in fact consists of two systems: (1) a composite "dark/cool" term that comes right up into the yellows and a "white/red" term that picks up the rest, thus exhausting the color space; and (2) highly restricted "black," "white," "red," and "yellow" terms that do not partition the space and are derived from ochre names. This last system, which might be considered to consist of nonBCTs, resembles the only available system in Rossel.

41. See also Senft 1987 with a large age-stratified sample.

42. It seems also appropriate, then, that in contrast to the quarrels between Newton and compatriots about how many colors there are in the rainbow, Rossel people used to believe that the rainbow is the blood of a recently murdered victim (Armstrong 1928:121).

43. For an excellent overview of the history of the unusual preoccupation with color in Western art, technology, and philosophy, see Gage 1999.

44. He goes on to speculate that, if the $\mathrm{EH}$ is shown to be tenable, there may be specific universal tendencies, as in the succulence-greenness association, or (on the basis of hints in the WCS) for black, white, and red BCTs to evolve while sharing the partition of the color space with non-BCTs.

\section{References Cited}

\section{Armstrong, W.E.}

1928 Rossel Island: An Ethnographical Study. Cambridge: Cambridge University Press.

Bartlett, Elsa Jaffe

1978 The Acquisition of the Meaning of Colour Terms. In Recent Advances in the

Psychology of Language. Robin Campbell and Philip T. Smith, eds. Pp. 89-108.

London: Plenum Press.

Berlin, Brent, and Elois Ann Berlin

1975 Aguaruna Color Categories. American Ethnologist 2(1):61-87.

Berlin, Brent, and Paul Kay

1991[1969] Basic Color Terms. Berkeley: University of California Press.

Bornstein, Marc H.

1973 Color Vision and Color Naming: A Psychophysiological Hypothesis of

Cultural Difference. Psychological Bulletin 80:257-285.

Boster, James

1986 Can Individuals Recapitulate the Evolutionary Development of Color Lexicons? Ethnology 25(1):61-74.

Buck, Carl Darling

1947 A Dictionary of Selected Synonyms in the Principal Indo-European Languages. Chicago: University of Chicago Press. 
Burgess, D., W. Kempton, and Robert MacLaury

1985 Tarahumara Color Modifiers: Individual Variation and Evolutionary

Change. In Directions in Cognitive Anthropology. J. Dougherty, ed. Pp. 49-72.

Chicago: University of Illinois Press.

Byrne, Alex, and David Hilbert, eds.

1997 Readings on Color. 2 vols. Cambridge, MA: MIT Press.

Casson, Ronald W.

1997 Color Shift: Evolution of English Color Terms from Brightness to Hue. In

Color Categories in Thought and Language. Clyde L. Hardin and Luisa Maffi, eds. Pp. 224-239. Cambridge: Cambridge University Press.

Collier, George

1976 Further Evidence for Universal Color Categories. Language 52(4):884-890.

Conklin, Harold

1955 Hanunóo Color Categories. Southwest Journal of Anthropology 11:339-344.

Crawford, T.D.

1982 Defining "Basic Color Term." Anthropological Linguistics 24:338-343.

Cruse, David A.

1986 Lexical Semantics. Cambridge: Cambridge University Press.

D'Andrade, Roy

1989 Cultural Cognition. In Foundations of Cognitive Science. M. I. Posner, ed.

Pp. 795-830. Cambridge, MA: MIT Press.

Davies, Ian, and Greville Corbett

1994 The Basic Color Terms of Russian. Linguistics 32(1):65-89.

1995 A Practical Field Method for Identifying Probable Basic Color Terms. Languages of the World 9(1):25-36.

1998 A Cross-Cultural Study of Color-Grouping: Tests of the Perceptual-Physiology Account of Color Universals. Ethos 26(3):338-360.

Davies, Ian, C. Macdermid, Greville Corbett, D. Jerrett, T. Jerrett, H. McGurle, P. T.

Sowden

1992 Color Terms in Setswana: A Linguistic and Perceptual Approach. Linguistics 30:1065-1103.

Derrig, Sandra

1978 Metaphor in the Color Lexicon. In Papers from the Parasession on the Lexicon, Chicago Linguistic Society. D. Farkas, W. M. Jacobsen, and K. W. Todrys, eds. Pp. 85-96. Chicago: Chicago Linguistic Society.

Dixon, Robert M. W.

1982 Where Have All the Adjectives Gone? and Other Essays in Syntax and Semantics. Berlin: Mouton.

Dougherty, Janet

1977 Color Categorization in West Futunese. In Sociocultural Dimensions of Language Change. B. Blount and M. Sanches, eds. Pp. 103-180. Cambridge, MA: Academic Press.

1978 On the Significance of a Sequence in the Acquisition of Basic Color Terms. In Recent Advances in the Psychology of Language. R. Campbell and P. T. Smith, eds. Pp. 133-148. London: Plenum Press.

Evans, Nicholas D.

1992 Kayardild Dictionary and Thesaurus: A Vocabulary of the Language of the Bentnick Islanders, North-West Queensland. Melbourne: University of Melbourne, Department of Linguistics and Language Studies. 
Frege, Gottlob

1953[1884] The Foundations of Arithmetic. New York: Harper and Row.

Fukui, Katsuyoshi

1996 Co-Evolution between Humans and Domesticates: The Cultural Selection of Animal Coat-Colour Diversity among the Bodi. In Redefining Nature. R. Ellen and F. Fukui, eds. Pp. 319-386. Oxford: Berg.

Furbee, N. Louanna, Kelly Maynard, J. Jerome Smith, Robert A. Benfer Jr., Sarah Quick, and Larry Ross

1997 The Emergence of Color Cognition from Color Perception. Journal of Linguistic Anthropology 6(2):223-240.

Gage, John

1999 Colour and Meaning. London: Thames and Hudson.

Goodwin, Charles

1996 Practices of Color Classification. Ninchikagaku "Cognitive Science" 3(2): 62-82.

Hardin, Clyde L., and Luisa Maffi, eds.

1997 Color Categories in Thought and Language. Cambridge: Cambridge University Press.

Harkness, Sara

1973 Universal Aspects of Learning Color Codes. Ethos 1:175-200.

Harnish, Robert

1991 Logical Form and Implicature. In Pragmatics. S. Davis, ed. Pp. 316-364. Oxford: Oxford University Press.

Heider, Eleanor Rosch

1971 "Focal" Color Areas and the Development of Color Names. Developmental Psychology (3):447-455.

1972 Probabilities, Sampling and Ethnographic Method. Man (n.s.) 7:448-466.

Heider, Eleanor Rosch, and Donald Olivier

1972 The Structure of the Color Space in Naming and Memory for Two Languages. Cognitive Psychology 3:337-354.

Henderson, James

1995 Phonology and Grammar of Yele, Papua New Guinea. Pacific Linguistics, Series B, 112.

Henderson, James, and Anne Henderson

1987 Nt:u kpu dyuu u puku dmi. Dictionaries of Papua New Guinea: Rossel

Language, Milne Bay. Ukarumpa, Papua New Guinea: SIL.

Ishihara, Shinobu

1996 The Series of Plates Designed as a Test for Colour-Deficiency. Tokyo: Kanehara.

Jameson, Kimberly, and Roy D'Andrade

1997 It's Not Really Red, Green, Yellow, Blue: An Inquiry into Perceptual Color Space. In Color Categories in Thought and Language. Clyde L. Hardin and Luisa Maffi, eds. Pp. 295-319. Cambridge: Cambridge University Press.

Jones, Rhys, and Betty Meehan

1975 Anberra Concept of Color. In Australian Aboriginal Concepts. L. R. Hiatt, ed. Pp. 20-39. Canberra: Australian Institute of Aboriginal Studies.

Kay, Paul

1975 Synchronic Variability and Diachronic Change in Color Terms. Language in Society 4:257-270. 
1999 The Emergence of Basic Color Lexicons Hypothesis: A Comment on "The Vocabulary of Colour with Particular Reference to Ancient Greek and Classical Latin" by John Lyons. In The Language of Color in the Mediterranean: An Anthology on Linguistic and Ethnographic Aspects of Color Terms. A. Borg, ed. Pp. 76-90. Stockholm: Almqvist and Wiksell.

Kay, Paul, and Brent Berlin

1997 Science $\neq$ Imperialism: Response to Saunders and van Brakel. Behavioral and Brain Sciences 20(2):196-201.

Kay, Paul, Brent Berlin, Luisa Maffi, and William Merrifield

1997 Color Naming across Languages. In Color Categories in Thought and Lan-

guage. Clyde L. Hardin and Luisa Maffi, eds. Pp. 21-56. Cambridge: Cambridge University Press.

Kay, Paul, Brent Berlin, and William Merrifield

1991 Biocultural Implications of Systems of Color Naming. Journal of Linguistic

Anthropology 1(1):12-25.

Kay, Paul, and Willett Kempton

1984 What Is the Sapir-Whorf Hypothesis? American Anthropologist 86:65-79.

Kay, Paul, and Luisa Maffi

1999 Color Appearance and the Emergence and Evolution of Basic Color Lexi-

cons. American Anthropologist 101(4):743-760.

Kay, Paul, and Chad McDaniel

1978 The Linguistic Significance of the Meanings of Basic Color Terms. Lan-

guage 54(3):610-646.

Kuschel, Rolf, and Torben Monberg

1974 "We Don't Talk Much about Color Here": A Study of Color Semantics on

Bellona Island. Man (n.s.) 9:213-242.

Lamb, Trevor, and Janine Bourriau, eds.

1994 Colour: Art and Science. Cambridge: Cambridge University Press.

Lewis, David

1969 Convention: A Philosophical Study. Cambridge, MA: Harvard University Press.

Lucy, John

1992 Language Diversity and Thought. Cambridge: Cambridge University Press.

1997a The Linguistics of "Color." In Color Categories in Thought and Language.

Clyde L. Hardin and Luisa Maffi, eds. Pp. 320-346. Cambridge: Cambridge University Press.

1997b Linguistic Relativity. Annual Review of Anthropology 26:291-312.

Lucy, John, and Richard Shweder

1979 Whorf and His Critics. American Anthropologist 81:581-615.

Lumsden, Charles J.

1985 Color Categorization: A Possible Concordance between Genes and Cul-

ture. Proceedings of the National Academy of Science 82:5805-5808.

Lyons, Sir John

1995 Colour in Language. In Colour: Art and Science. T. Lamb and J. Bourriau, eds. Pp. 194-224. Cambridge: Cambridge University Press.

1999 The Vocabulary of Colour with Particular Reference to Ancient Greek and Classical Latin. In The Language of Color in the Mediterranean: An Anthology 
on Linguistic and Ethnographic Aspects of Color Terms. A. Borg, ed. Pp. 38-75. Stockholm : Almqvist and Wiksell.

MacLaury, Robert

1987 Color-Category Evolution and Shuswap Yellow-with-Green. American Anthropologist 89(1):107-124.

1991 Exotic Color Categories: Linguistic Relativity to What Extent? Journal of Linguistic Anthropology 1(1):26-51.

1992 From Brightness to Hue. Current Anthropology 33(2):137-186.

1997 Color and Cognition in Mesoamerica. Austin: University of Texas Press.

Maffi, Luisa

1990 Somali Color Term Evolution: Grammatical and Semantic Evidence. Anthropological Linguistics 32(3-4):316-334.

Miller, George, and Philip Johnson-Laird

1976 Language and Perception. Cambridge: Cambridge University Press.

Moss, A. E.

1989 Basic Color Terms. Lingua 78:313-320.

Rosch, Eleanor

1977 Linguistic Relativity. In Thinking: Readings in Cognitive Science. P. Johnson-Laird and P. Wason, eds. Pp. 501-519. Cambridge: Cambridge University Press.

Sacks, Oliver

1996 The Island of the Color Blind. London: Picador.

Saunders, Barbara

1992 The Invention of Basic Color Terms. Utrecht, the Netherlands: ISOR.

Saunders, Barbara, and J. van Brakel

1997 Are There Non-Trivial Constraints on Color Categorization? (With Commentary). Behavioral and Brain Sciences 20(2):167-212.

Senft, Gunter

1987 Kilivila Color Terms. Studies in Language 11(2):313-346.

Shepard, Roger N.

1992 The Perceptual Organization of Colors. In The Adapted Mind. J. Barkow, L.

Cosmides, and J. Tooby, eds. Pp. 495-532. Oxford: Oxford University Press.

Wetzer, Harrie

1995 Nouniness and Verbiness: A Typological Study of Adjectival Predication.

Nijmegen, the Netherlands: Universiteitsdrukkerij.

Wierzbicka, Anna

1996 Semantics: Primes and Universals. Oxford: Oxford University Press.

Wittgenstein, Ludwig

1958 Philosophical Investigations. London: Macmillan.

Max Planck Institute for Psycholinguistics

PB310

NL 6500 AH Nijmegen, The Netherlands

Stephen.Levinson Ompi.nl 